\title{
Energy-efficient MAC protocols for wireless sensor networks: a survey
}

\section{Farhana Afroz* and Robin Braun}

School of Electrical and Data Engineering,

University of Technology Sydney,

Broadway, NSW 2007, Australia

Email: farhana.afroz-1@student.uts.edu.au

Email: Robin.Braun@uts.edu.au

${ }^{*}$ Corresponding author

\begin{abstract}
Wireless sensor network (WSN) is a network of a large number of battery-powered tiny sensor nodes wirelessly connected together to facilitate a wide range of monitoring applications. As WSN nodes are energy-constrained microelectronic devices, the primary design objective of WSNs is to minimise energy consumption to prolong the network lifetime. To achieve this goal, a range of cross-layer techniques, particularly focusing on medium access control (MAC) sublayer, is proposed targeting different WSN applications. This paper aims to survey low-power WSN MAC protocols, proposed from 2000 to the present, emphasising some general aspects including the issues addressed, the solutions proposed, design principles, strengths, drawbacks and target applications. With this aim, we mainly classify the MAC protocols into three categories: contention-based protocols, time division multiple access (TDMA)-based protocols and hybrid protocols, where the first category is further subdivided into subclasses. The development trends and potential research challenges are also discussed.
\end{abstract}

Keywords: WSN; wireless sensor network; MAC protocols; energy efficiency; network lifetime; QoS; quality of service; duty cycling; CSMA; carrier sense multiple access; TDMA; time division multiple access; hybrid.

Reference to this paper should be made as follows: Afroz, F. and Braun, R. (2020) 'Energy-efficient MAC protocols for wireless sensor networks: a survey', Int. J. Sensor Networks, Vol. 32, No. 3, pp.150-173.

Biographical notes: Farhana Afroz received her MEStud degree with Telecommunication Engineering major from the University of Technology Sydney (UTS), Australia, in 2015, and the MS and BSc (Hons) degrees in Applied Physics, Electronics and Communication Engineering from the University of Dhaka, Bangladesh, in 2007 and 2005 respectively. Currently, she is pursuing her $\mathrm{PhD}$ at the School of Electrical and Data Engineering, UTS, Australia. She has been working as a Casual Academic at UTS since 2016. She was a Lecturer for the Department of Electronics and Telecommunication Engineering at University of Liberal Arts Bangladesh from 2007 to 2010. Her current research interests are in the field of wireless sensor networks, wireless communications, and $5 \mathrm{G}$ mobile networks.

Robin Braun received his BSc (Hons) from Brighton University, Brighton, UK, and the MSc (Engg.) and $\mathrm{PhD}$ degrees from the University of Cape Town, Cape Town, South Africa, in 1980, 1982, and 1986, respectively. He started his academic career in 1986 at the University of Cape Town. In 1998, he moved to the University of Technology, Sydney, Australia.Prior to moving to academia, he spent 10 years in industry, mostly with Philips and Plessey, where he worked on the design of precision electronic distance measuring equipment. His recent work has been in network protocols and the management of complex next generation networks. He is very active in Software Defined Networks, and is a founder member of ANZSDN.

\section{Introduction}

Technological advancements in wireless communications and digital electronics have opened enormous opportunities to deploy wireless sensor networks (WSNs) in different applications such as environment monitoring, event detection, health care, shipping container monitoring, etc. WSN applications usually require low-cost, low complex, ultra-lowpower wireless connectivity among portable fixed/moving devices over short distances with flexible throughput 
requirements. IEEE 802.15.4 low-rate wireless personal area network (LR-WPAN) devices are designed to be used in such applications (Gutiérrez et al., 2010).

Although the new application areas of WSN keep increasing due to its versatility, energy consumption is still a huge limitation for their practical implementations. A typical WSN, as shown in Figure 1, is a network of a large number of battery-powered tiny sensor nodes, generally scattered in a sensor field. Each sensor node can sense the environment, collect the information of interest from the sensor field, and forward the monitored information/data via multi-hop architecture to the sink where they can be processed or analysed (Akyildiz et al., 2002; Buratti et al., 2011). Some key features of WSNs include long network lifetime, selforganisation, scalability, flexible connectivity among nodes, self-healing, low complexity, low cost, small-sized nodes and mobility, among which prolonged network lifetime with low cost is the most crucial issue (Buratti et al., 2011; AlSkaif et al., 2017). WSN lifetime can be defined as the length of the time period starting from the network deployment to the ending of the battery lifetime of sensor nodes when the battery fails to provide sufficient energy required for sensing, processing or communication (Buratti et al., 2011). Thus, WSN lifetime is intrinsically related to the battery lifetime of sensor nodes.

Figure 1 A typical wireless sensor network (see online version for colours)

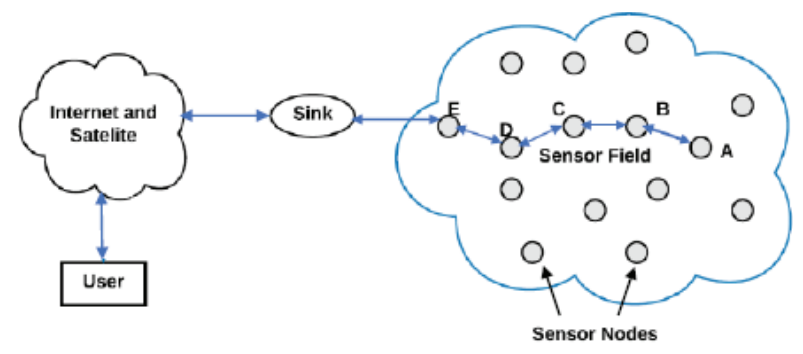

To prolong the battery lifetime of sensor nodes, typical WSNs need to be energy-aware. There are a couple of reasons behind this. Firstly, sensor nodes are usually batterypowered microelectronic devices consisting of four basic components namely sensing unit (composed of sensors and analog-to-digital converters), data processing unit, power unit and transceiver unit (Akkaya and Younis, 2005; Matin and Islam, 2012). As microelectronic devices are resourceconstrained, they are essentially equipped with low power sources (Akyildiz et al., 2002). Secondly, the cost of the battery is high. Thirdly, in many applications, WSNs are deployed in such environments that are not easily accessible. Considering these issues, therefore, it is generally not feasible to recharge or replace the battery, which in turn push researchers to find energy-preserving solutions by developing cross-layer techniques, particularly focusing on MAC sublayer. Sensor nodes powered by energy harvesting $(\mathrm{EH})$ system in which the ambient energy from heat, light, vibration, or RF energy is converted into electrical energy can also greatly enhance WSN lifetime. MAC protocol plays a critical role in designing both battery-powered WSN and energy-harvesting WSN (Sherazi et al., 2018).
The MAC protocols in WSNs focus on energy consumption issues together with adaptability, reliability, and scalability of the network. The MAC layer controls the way the sensor nodes transmit/receive data, and the way sensor nodes contend to access the medium. A wide range of MAC protocols is proposed in the literature for different WSN applications. However, no MAC protocol has been standardised by IEEE. The selection of MAC protocol is generally applicationspecific. The search for improving energy efficiency via energy-efficient MAC protocols while leaving the least impact on other aspects, such as latency and throughput, is an ongoing research challenge. The design and development of new WSN MAC protocols require the investigation of the existing MAC protocols proposed for WSNs addressing all potential sources of energy consumption.

A number of literature reviews have been conducted in Akyildiz et al. (2002), Naik and Sivalingam (2004), Demirkol et al. (2006), Langendoen (2008), Ali et al. (2008), Bachir et al. (2010), Langendoen and Meier (2010), Al Ameen et al. (2010), Yigitel et al. (2011), Suriyachai et al. (2011), Huang et al. (2012), Zhao et al. (2012), Khanafer et al. (2013), Chen et al. (2014), Alfayez et al. (2015), Kosunalp (2015), Djiroun and Djenouri (2016), Kaur and Kumar (2016), Muzakkari et al. (2018) and Quintero et al. (2019) to summarise different approaches of WSN MAC protocols. Akyildiz et al. (2002) survey protocols and algorithms proposed for sensor networks. In Naik and Sivalingam (2004), some early designed random access and static access-based MAC protocols are reviewed. The work in Demirkol et al. (2006) details the strengths and weaknesses of several MAC protocols along with the emphasis of some particular protocols that provide integration of MAC layer with other layers. A survey in Langendoen (2008) classifies WSN MAC protocols into four groups, namely random access, slotted access, frame-based and, hybrid protocols. The research paper in Bachir et al. (2010) proposes a thematic classification of WSN MAC protocols according to the problems they address. Yigitel et al. (2011) summarise QoS-aware MAC protocols proposed for mobile, underwater, and underground WSNs. In Suriyachai et al. (2011), a comparison of WSN MAC protocols proposed for mission-critical applications is provided. The evolution of MAC protocols proposed for WSNs over the period 2002-2011 is surveyed in Huang et al. (2012). Alfayez et al. (2015) reviews duty-cycled MAC protocols by classifying them into synchronous and asynchronous categories. In Djiroun and Djenouri (2016), asynchronous wake-up MAC protocols are reviewed by dividing them into three categories: duty-cycled wake-up, non-cycled wake-up, and path reservation wake-up. TDMA-based MAC protocols for cluster-based WSNs are surveyed in Kaur and Kumar (2016). One recently published work in Muzakkari et al. (2018) classifies some recent WSN MAC protocols into three categories, namely contention-based, scheduling-based and, hybrid. Another recent work in Quintero et al. (2019) evaluates the characteristics of several contemporary WSN MAC protocols to define the new criteria that should be accounted for designing new approaches. In this paper, we primarily classify WSN MAC protocols proposed over 2000 to date into three categories: contention-based, TDMA-based, 
and hybrid, where the first category is further subdivided into subclasses. We investigate different MAC protocols emphasising some general aspects, including the issues addressed and the solutions proposed in each protocol, their design principles, pros and cons, performances, and target applications.

The rest of the paper is organised as follows. The proposed taxonomy as well as a timeline of WSN MAC protocols are presented in Section 2. A number of contention-based MAC protocols are discussed in Section 3 by dividing them into two subclasses, namely synchronous and asynchronous protocols. Several TDMA-based and hybrid MAC protocols are reviewed in Sections 4 and 5, respectively. Finally, Section 6 concludes the paper summarising potential challenges.

\section{WSN medium access control}

A common goal of WSN research is to maximise network lifetime as sensor nodes eventually die if they are out of battery. Different categories of MAC schemes are proposed in the literature to minimise the major sources of energy consumption in WSN, namely collision, overhearing, control packet overhead, idle listening and overemitting (Ye et al., 2002; Demirkol et al., 2006). When more than one node tries to transmit their packets at the same time, collisions can happen in the medium. When a collision occurs, the corrupted packets need to be discarded followed by retransmissions, which increase energy consumption and latency in the network. The overhearing problem occurs when a node receives packets that are destined for other node(s). In most protocols, exchanging of control packets is required. As these control packets do not contain any application data, energy consumed for transmitting or receiving these packets is considered as overhead. Overemitting occurs when a sensor node transmits a message while its receiver is not ready to receive (Zurawski, 2017). Idle listening, the last major source of energy consumption, is the phenomena when a node continuously keeps its radio $\mathrm{ON}$ to receive possible traffic from its neighbour node. When nothing is sensed, sensor nodes remain in idle mode for a large fraction of time, which draws a considerable amount of energy (Van Dam and Langendoen, 2003).

A well-designed MAC protocol must need to adopt energy-efficient techniques that try to minimise the five major causes of energy consumption described above. Other attributes such as end-to-end packet delivery delay, throughput, fairness, or bandwidth utilisation are considered as secondary objectives for WSNs. In literature, WSN MAC protocols are primarily divided into three types as depicted in Figure 2: contention-based protocols, TDMAbased protocols, and hybrid protocols. Contention-based MAC is further divided into two subclasses: synchronous MAC and asynchronous MAC, where the later subclass can be of two categories, namely asynchronous MAC with one radio and MAC with wake-up radio (WuR). A timeline of WSN MAC protocols is depicted in Figure 3. The following sections will discuss MAC protocols from each of these categories.
Figure 2 Classification of WSN MAC protocols (see online version for colours)



3 Contention-based MAC protocols

Contention-based MAC schemes are mainly based on carrier sense multiple access (CSMA) protocol. The basis of CSMA is to listen (or sense) the medium before transmitting any traffic. This kind of MAC protocols tries to reduce energy consumption by regulating the operation activity (i.e., sleep/listen) of sensor nodes. One widely used technique to control node's operation activity is Duty Cycling (DuC) in which a node toggles between active mode (radio is ON) and sleep mode (radio is OFF). When a sensor node is in active mode, it normally drains a considerable amount of power from its battery. For this reason, sensor nodes need to be in active state for the shortest possible period of time to conserve energy (Buratti et al., 2011). In other words, instantaneous power delivery from the battery should be extremely low to save energy. This can be achieved by maintaining low duty cycle, where the duty cycle is actually the ratio of active period and the summation of active period and sleeping period. Low duty cycle reduces energy consumption; however, it increases the end-to-end delay as the waiting period at each hop increases. Higher duty cycling can reduce delay, but at the cost of consuming more energy.

Contention-based MAC protocols can be divided into synchronous protocols and asynchronous protocols. In synchronous MAC protocols, sensor nodes periodically wake up at the same time and exchange traffic in common active periods. Synchronising with neighbouring nodes to wake up at the same time is a natural approach to establish energyefficient communication between WSN nodes. However, it causes additional synchronisation overhead. In asynchronous MAC protocol, nodes individually can set their wakeup schedule without introducing synchronisation overhead. However, this type of approach needs a coordination mechanism among nodes so that the neighbouring nodes can meet one-another's schedule. Asynchronous MAC protocols can be further subdivided into MAC with one radio and MAC with WuR. In MAC with one radio, a node starts by sending a preamble. In MAC with WuR, nodes stay in sleep mode all the time while the WuR keeps monitoring the channel. When a node has data to transmit to its neighbour, it initiates by transmitting a short wake-up message to it (Djiroun and 
Figure 3 A timeline of WSN MAC protocols (see online version for colours)

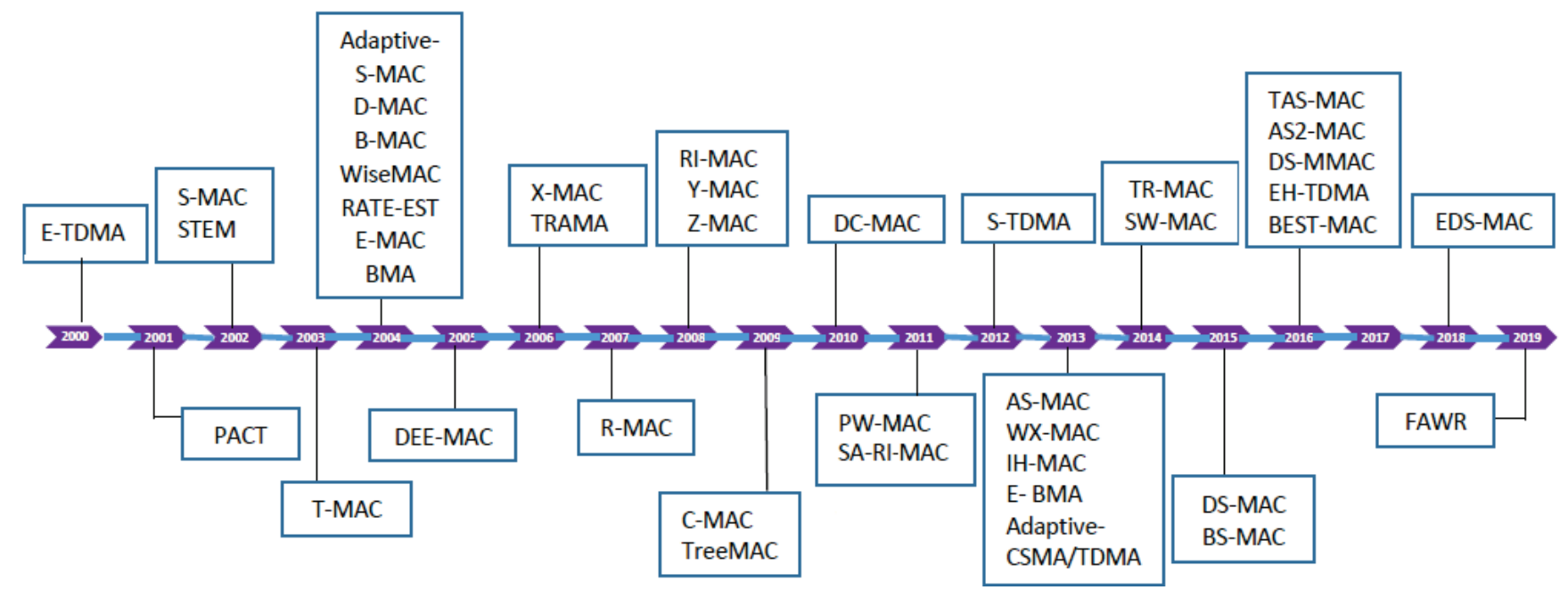

Djenouri, 2016). Several contention-based MAC protocols are elaborated in following subsections. Table 1 summarises some features of considered contention-based WSN MAC protocols.

\subsection{Synchronous MAC protocols}

In synchronous MAC scheme, a WSN node in wake-up mode listens to the medium for a certain period of time to hear its neighbours' schedule. If it cannot detect any schedule from its neighbouring nodes, it sets its following wake-up time and broadcasts it. In this way, a node becomes a synchroniser. In cluster-based WSNs, a WSN is normally split into a large number of groups, each of which is called cluster. All sensor nodes within a cluster get synchronised with a synchroniser, which is usually one/few hop(s) away from them. In case a WSN node receives a schedule from its neighbour prior to deciding its own schedule, it acts as a follower of the received schedule. When a sensor node receives a different schedule after choosing its own schedule, it follows both schedules so as it can act as a bridge node between clusters. A bridge node wakes up at the time when its own cluster head or adjacent cluster head wakes up (Huang et al., 2012). A node in sleeping mode turns its radio off till its next wake-up time arrives.

A number of contention-based synchronous MAC protocols such as S-MAC, T-MAC, D-MAC, R-MAC, TASMAC and AS2-MAC are proposed in the literature. These are briefly summarised as below.

\section{$S-M A C$}

The first duty-cycling WSN MAC protocol, namely SensorMAC (S-MAC), is proposed in Ye et al. (2002). S-MAC is a synchronous MAC protocol, which is designed to reduce energy consumption as compared with IEEE 802.11 while providing collision avoidance and good scalability. The design goal is achieved by developing three major modules in SMAC, namely collision and overhearing avoidance, periodic listen/sleep, and message passing. Since in many WSN applications, sensor nodes remain in idle mode for a long duration when nothing is sensed, S-MAC tries to minimise the listen time by implementing periodic listen/sleep mechanism that lets the sensor node go to sleep mode periodically. Hidden terminal problem is minimised by adopting request to send/clear to send (RTS/CTS) mechanism. The application of in-channel signaling to let each sensor node go to sleep when its neighbour node is sending to other node ensures overhearing avoidance. For efficient transmission (from both energy and latency perspective) of long messages, the message passing approach is adopted in which a long message is fragmented into a number of small fragments that are transmitted in burst.

In S-MAC, time is divided into number of frames, each of which is further split into three periods: SYNC, DATA and SLEEP. All nodes have fixed wake-up time and sleep time. At the start of the SYNC period, all nodes within a cluster wake up to get their clocks synchronised with each other. In the DATA period, multiple nodes with data packets to transmit to a node contend for the medium using the RTS/CTS mechanism. Nodes with no data to send go back to sleep at the beginning of the SLEEP period. Other nodes will turn off its radio after finishing data transmission.

Results in Ye et al. (2002) show that S-MAC has very good energy-conserving characteristics as compared with IEEE 802.11 protocols. However, one drawback of S-MAC is the end-to-end latency caused by periodic sleeping, particularly when a network has heavy traffic. S-MAC supports only one-hop data forwarding per cycle. This shortcoming is addressed in Ye et al. (2004) by introducing an adaptive listening mechanism to S-MAC. Adaptive listening allows the sensor node overhearing its neighbour to wake up for a short duration at the end of the transmission. With this, the neighbouring node can immediately pass its traffic to the node without waiting for its periodic listen time if the node is its neighbour's next-hop node. In this way, the delay for the next transmission is reduced. However, S-MAC with adaptive listening can forward a data packet by at most two-hops in each cycle. Thereby, a considerable amount of 
delay puts restrictions to S-MAC for delay-sensitive WSN applications.

\section{T-MAC}

An adaptive energy-efficient WSN MAC protocol named Timeout-MAC (T-MAC) is proposed in Van Dam and Langendoen (2003). T-MAC aims to minimise energy consumption on idle listening by introducing an adaptive duty cycle method. The major difference between S-MAC and TMAC is that S-MAC uses fixed duty cycle, whereas T-MAC employs adaptive active times (shown in Figure 4). When the duty cycle is fixed, the listen and sleep periods in active/sleep duty cycle are static and predefined, which can cause high delay and lower throughput under variable traffic conditions. In S-MAC, the sensor nodes in active mode remain awake over the entire active period irrespective of whether they are transmitting/receiving data or not. In T-MAC, the active/listen period ends when there is no activation event occurred for the duration of TA (Figure 4), where TA is the minimum duration of idle listening before returning to sleep.

Figure 4 (a) The S-MAC duty cycle; the arrows represent transmitted and received messages and (b) The T-MAC scheme with adaptive active times

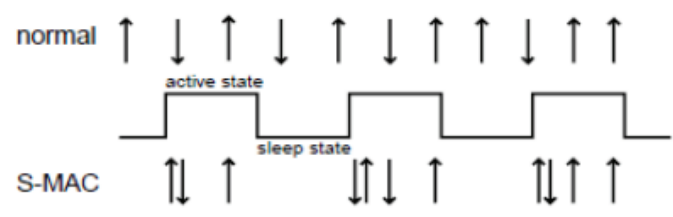

(a)

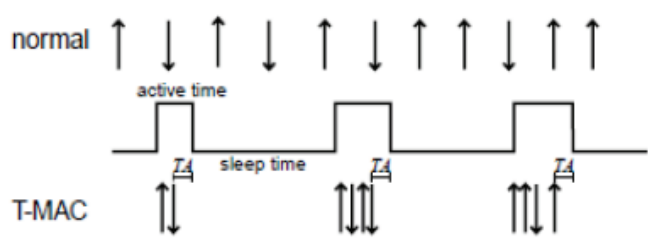

(b)

Source: Van Dam and Langendoen (2003)

A problem associated with T-MAC scheme, namely the early sleeping problem, is also identified in Van Dam and Langendoen (2003), and a solution (future request-to-send, FRTS and full buffer priority) of this problem is proposed accordingly. In T-MAC, through FRTS packet, a node can notify its target that it is not able to access the channel at this time. To discuss T-MAC's control behaviour, let us consider there are 4 nodes, namely $A 1, A 2, A 3$, and $A 4$ in the network. When a TMAC node $A l$ has data to transmit to node $A 2$, it sends an RTS packet. Upon receiving the RTS packet, node $A 2$ needs to acknowledge by sending a CTS packet to its source node. At the same time, A2's neighbour node $A 3$ overhears the acknowledgement (i.e., CTS message) and sends an FRTS packet to its receiver $A 4$. The FRTS packet carries the duration of current data transmission from node $A 1$ to $A 2$, thereby allows $A 4$ to learn when to wake-up. Node $A 4$ goes back to sleep after receiving the FRTS packet. When the data communication between node $A l$ and $A 2$ is finished, $A 4$ wakes up to receive the data packet from $A 3$. During the time node $A 3$ transmits FRTS, $A 1$ postpones its transmission and sends a DS (Data-Send) packet having the identical size of FRTS to $A 2$ to inhibit any neighbouring node from accessing the channel. As there is no useful information carried by the DS packet, the collision of DS and FRTS at $A 2$ is not a problem.

S-MAC and T-MAC achieve similar energy performances under homogeneous traffic loads. Under variable traffic load scenario, T-MAC shows better performance compared with S-MAC by a factor of 5 . However, similar to S-MAC, with T-MAC, the sensor nodes that are on a multi-hop path to the sink cannot be notified about the traffic in progress. Thus, after several hops, packet forwarding may halt. This problem is named as data forwarding interruption in Lu et al. (2004), which is discussed below.

\section{D-MAC}

In WSN, the process of collecting data from source nodes to a sink through a unidirectional data-gathering tree is called convergecast. In Lu et al. (2004), an adaptive energy-efficient and low-latency MAC protocol, namely D-MAC, is proposed, which is designed for convergecast communication. D-MAC tries to subside the data forwarding interruption problem associated with previously proposed MAC protocols (such as S-MAC and T-MAC) that use low activation/sleep duty cycles to minimise energy consumption. When sensor nodes on a multi-hop path to the sink are not aware of ongoing data transmission and go to sleep mode till the next cycle/interval arrives, a data forwarding interruption problem occurs causing a considerable amount of sleep delay for packet delivery. DMAC overcomes this shortcoming by staggering active/sleep schedule of the sensor nodes depending on its depth in the data gathering tree, thereby allowing continuous packet forwarding. The data prediction method is used to solve the sleep delay problem. More to Send packet mechanism is employed for the scenario when the same level nodes in the data gathering tree (having different parents) compete with each other to get access to the medium.

Simulation results in $\mathrm{Lu}$ et al. (2004) show that by implementing data gathering trees in WSN, D-MAC can provide remarkable energy savings as well as low delay while guaranteeing high reliability in data delivery. Since D-MAC shows less network latency as compared with other sleep/listen MAC protocols, for delay-sensitive applications, D-MAC can be a good choice. However, D-MAC does not implement collision avoidance method. Therefore, when several sensor nodes having the same schedule try to transmit to the same node, collisions may happen. Another problem is, if the data transmission paths are not known in advance, the data gathering tree formation may not be possible.

\section{$R-M A C$}

Duty-cycled MAC protocols are aimed to meet the energy requirements of WSNs. However, they incorporate a considerable amount of end-to-end packet delivery latency, limited throughput and poor contention handling. To address these problems, R-MAC (Routing-enhanced MAC) 
Table 1 Contention-based WSN MAC protocols

\begin{tabular}{|c|c|c|c|c|}
\hline Protocols & Protocol type & Issues addressed & Performance & Target applications \\
\hline $\begin{array}{l}\text { S-MAC (Ye } \\
\text { et al., 2002) }\end{array}$ & Synchronous MAC & $\begin{array}{l}\text { Collision, idle listening, control } \\
\text { packet overhead, and } \\
\text { overhearing }\end{array}$ & Reduces energy consumption & $\begin{array}{l}\text { Multi-hop ad-hoc } \\
\text { WSNs }\end{array}$ \\
\hline $\begin{array}{l}\text { STEM } \\
\text { (Schurgers } \\
\text { et al., 2002) }\end{array}$ & $\begin{array}{l}\text { Asynchronous } \\
\text { MAC with WuR }\end{array}$ & $\begin{array}{l}\text { Multi-hop packet forwarding } \\
\text { while nodes are in sleeping } \\
\text { mode }\end{array}$ & $\begin{array}{l}\text { Trades-off energy savings with } \\
\text { path set-up latency }\end{array}$ & $\begin{array}{l}\text { Event monitoring } \\
\text { (multi-hop) }\end{array}$ \\
\hline $\begin{array}{l}\text { T-MAC (Van } \\
\text { Dam and } \\
\text { Langendoen, } \\
\text { 2003) }\end{array}$ & Synchronous MAC & $\begin{array}{l}\text { Fixed duty cycling and early } \\
\text { sleeping problem }\end{array}$ & $\begin{array}{l}\text { Shows better energy performance } \\
\text { compared with S-MAC by a factor } \\
\text { of } 5 \text { (under variable traffic load } \\
\text { scenario) }\end{array}$ & $\begin{array}{l}\text { Multi-hop WSN with } \\
\text { variable loads }\end{array}$ \\
\hline $\begin{array}{l}\text { D-MAC (Lu } \\
\text { et al., 2004) }\end{array}$ & Synchronous MAC & $\begin{array}{l}\text { Data forwarding interruption } \\
\text { problem }\end{array}$ & $\begin{array}{l}\text { Minimises delay without } \\
\text { sacrificing energy performance }\end{array}$ & $\begin{array}{l}\text { Convergecast } \\
\text { communication } \\
\text { (multi-hop) }\end{array}$ \\
\hline $\begin{array}{l}\text { B-MAC } \\
\text { (Polastre et al., } \\
\text { 2004) }\end{array}$ & $\begin{array}{l}\text { Asynchronous } \\
\text { MAC with one } \\
\text { radio }\end{array}$ & $\begin{array}{l}\text { Idle listening, collision, and } \\
\text { channel utilisation }\end{array}$ & $\begin{array}{l}\text { Provides better throughput, packet } \\
\text { delivery rates, lower delay, and less } \\
\text { energy consumption as compared } \\
\text { with SMAC }\end{array}$ & $\begin{array}{l}\text { Monitoring } \\
\text { applications } \\
\text { (multi-hop) }\end{array}$ \\
\hline $\begin{array}{l}\text { WiseMAC } \\
\text { (El-Hoiydi and } \\
\text { Decotignie, } \\
\text { 2005) }\end{array}$ & $\begin{array}{l}\text { Asynchronous } \\
\text { MAC with one } \\
\text { radio }\end{array}$ & $\begin{array}{l}\text { Idle listening, collision, long } \\
\text { preamble problem and } \\
\text { overhead }\end{array}$ & $\begin{array}{l}\text { Reduces power consumption } \\
\text { compared with PSM }\end{array}$ & $\begin{array}{l}\text { Infrastructure WSNs } \\
\text { (Downlink) }\end{array}$ \\
\hline $\begin{array}{l}\text { RATE-EST } \\
\text { (Miller and } \\
\text { Vaidya, 2004) }\end{array}$ & $\begin{array}{l}\text { Asynchronous } \\
\text { MAC with WuR }\end{array}$ & $\begin{array}{l}\text { Problems associated with the } \\
\text { conventional wake-up } \\
\text { procedure }\end{array}$ & $\begin{array}{l}\text { Shows better energy savings } \\
\text { compared with STEM }\end{array}$ & $\begin{array}{l}\text { Single-hop } \\
\text { communication }\end{array}$ \\
\hline $\begin{array}{l}\text { X-MAC } \\
\text { (Buettner et al., } \\
\text { 2006) }\end{array}$ & $\begin{array}{l}\text { Asynchronous } \\
\text { MAC with one } \\
\text { radio }\end{array}$ & $\begin{array}{l}\text { Problems associated with low } \\
\text { power listening }\end{array}$ & $\begin{array}{l}\text { Minimises latency and power } \\
\text { consumption, and improves } \\
\text { throughput }\end{array}$ & $\begin{array}{l}\text { Multi-hop WSNs } \\
\text { with dynamic traffic } \\
\text { loads }\end{array}$ \\
\hline $\begin{array}{l}\text { R-MAC (Du } \\
\text { et al., 2007) }\end{array}$ & Synchronous MAC & $\begin{array}{l}\text { Problems associated with } \\
\text { duty-cycled protocols }\end{array}$ & $\begin{array}{l}\text { Reduce latency and improves } \\
\text { contention handling without } \\
\text { limiting energy efficiency and } \\
\text { throughput }\end{array}$ & $\begin{array}{l}\text { Event monitoring } \\
\text { applications } \\
\text { (multi-hop) }\end{array}$ \\
\hline $\begin{array}{l}\text { RI-MAC (Sun } \\
\text { et al., 2008) }\end{array}$ & $\begin{array}{l}\text { Asynchronous } \\
\text { MAC with one } \\
\text { radio }\end{array}$ & $\begin{array}{l}\text { Latency and long preamble } \\
\text { problem }\end{array}$ & $\begin{array}{l}\text { Minimises latency, and improves } \\
\text { throughput and packet delivery } \\
\text { ratio as compared with X-MAC }\end{array}$ & $\begin{array}{l}\text { WSNs with dynamic } \\
\text { traffic loads }\end{array}$ \\
\hline $\begin{array}{l}\text { C-MAC (Liu } \\
\text { et al., 2009) }\end{array}$ & $\begin{array}{l}\text { Asynchronous } \\
\text { MAC with one } \\
\text { radio }\end{array}$ & Overhead and latency & $\begin{array}{l}\text { Reduces energy consumption, } \\
\text { latency and improves throughput } \\
\text { compared with B-MAC, S-MAC, } \\
\text { and GeRaF }\end{array}$ & $\begin{array}{l}\text { Event tracking and } \\
\text { surveillance }\end{array}$ \\
\hline $\begin{array}{l}\text { DC-MAC } \\
\text { (Zheng et al., } \\
2010 \text { ) }\end{array}$ & $\begin{array}{l}\text { Asynchronous } \\
\text { MAC with WuR }\end{array}$ & $\begin{array}{l}\text { Collision, idle listening, control } \\
\text { packet overhead, overhearing, } \\
\text { and latency }\end{array}$ & $\begin{array}{l}\text { Reduces latency and conserves } \\
\text { more energy compared with } \\
\text { S-MAC and GeRaF }\end{array}$ & Multi-hop WSNs \\
\hline $\begin{array}{l}\text { PW-MAC } \\
\text { (Tang et al., } \\
\text { 2011) }\end{array}$ & $\begin{array}{l}\text { Asynchronous } \\
\text { MAC with one } \\
\text { radio }\end{array}$ & $\begin{array}{l}\text { Collision and timing challenges } \\
\text { occurred by clock drift, } \\
\text { operating system delays and } \\
\text { unstable hardware }\end{array}$ & $\begin{array}{l}\text { Shows better latency and packet } \\
\text { delivery ratio performance as } \\
\text { compared with X-MAC, WiseMAC } \\
\text { and RI-MAC }\end{array}$ & $\begin{array}{l}\text { WSNs under } \\
\text { single-hop or } \\
\text { multi-hop traffic } \\
\text { flows }\end{array}$ \\
\hline $\begin{array}{l}\text { SA-RI-MAC } \\
(\text { Henna, 2011) }\end{array}$ & $\begin{array}{l}\text { Asynchronous } \\
\text { MAC with one } \\
\text { radio }\end{array}$ & $\begin{array}{l}\text { Handling traffic contention } \\
\text { under dynamic traffic loads } \\
\text { without limiting energy } \\
\text { efficiency }\end{array}$ & $\begin{array}{l}\text { Enhances fairness among the } \\
\text { sending nodes, reduces latency and } \\
\text { energy consumption, and provides } \\
\text { higher delivery ratio compared } \\
\text { with RI-MAC }\end{array}$ & $\begin{array}{l}\text { Event monitoring } \\
\text { under dynamic traffic } \\
\text { load conditions }\end{array}$ \\
\hline $\begin{array}{l}\text { DCW-MAC } \\
\text { (Mazloum and } \\
\text { Edfors, 2011) }\end{array}$ & $\begin{array}{l}\text { Asynchronous } \\
\text { MAC with WuR }\end{array}$ & $\begin{array}{l}\text { Energy consumption and } \\
\text { network lifetime }\end{array}$ & $\begin{array}{l}\text { Shows better energy performance } \\
\text { as compared with X-MAC and } \\
\text { always-on WRx MAC under low } \\
\text { traffic scenario }\end{array}$ & $\begin{array}{l}\text { Low-power WSN } \\
\text { applications }\end{array}$ \\
\hline $\begin{array}{l}\text { AS-MAC (Jang } \\
\text { et al., 2013) }\end{array}$ & $\begin{array}{l}\text { Asynchronous } \\
\text { MAC with one } \\
\text { radio }\end{array}$ & $\begin{array}{l}\text { Overhearing, latency and } \\
\text { overhead }\end{array}$ & $\begin{array}{l}\text { Shows better energy performance } \\
\text { and reduces delay and packet loss } \\
\text { as compared with SCP-MAC }\end{array}$ & Multi-hop WSNs \\
\hline
\end{tabular}


Table 1 Contention-based WSN MAC protocols (continued)

\begin{tabular}{|c|c|c|c|c|}
\hline Protocols & Protocol type & Issues addressed & Performance & Target applications \\
\hline $\begin{array}{l}\text { WX-MAC } \\
\text { (Han et al., } \\
\text { 2013) }\end{array}$ & $\begin{array}{l}\text { Asynchronous } \\
\text { MAC with one } \\
\text { radio }\end{array}$ & $\begin{array}{l}\text { Preamble length, overhearing } \\
\text { and the duration of the wake-up } \\
\text { state }\end{array}$ & $\begin{array}{l}\text { Shows better energy performance } \\
\text { as compared with B-MAC, } \\
\text { WiseMAC and X-MAC }\end{array}$ & $\begin{array}{l}\text { Low-power WSN } \\
\text { applications }\end{array}$ \\
\hline SW-MAC & Asynchronous & End-to-end packet delivery & Shortens the end-to-end delivery & Event monitoring \\
\hline $\begin{array}{l}\text { (Liang et al., } \\
\text { 2014) }\end{array}$ & $\begin{array}{l}\text { MAC with one } \\
\text { radio }\end{array}$ & $\begin{array}{l}\text { latency, idle listening, collision } \\
\text { and overhearing }\end{array}$ & $\begin{array}{l}\text { latency without sacrificing energy } \\
\text { performance }\end{array}$ & $\begin{array}{l}\text { with dynamic traffic } \\
\text { patterns (multi-hop) }\end{array}$ \\
\hline TR-MAC & Asynchronous & Idle listening, control packet & Outperforms X-MAC and & Low data rate \\
\hline $\begin{array}{l}\text { (Morshed and } \\
\text { Heijenk, 2014) }\end{array}$ & $\begin{array}{l}\text { MAC with one } \\
\text { radio }\end{array}$ & $\begin{array}{l}\text { overhead, collision and } \\
\text { preamble length }\end{array}$ & $\begin{array}{l}\text { WiseMAC in terms of energy } \\
\text { efficiency }\end{array}$ & applications \\
\hline $\begin{array}{l}\text { DS-MAC } \\
\text { (Wang et al., } \\
\text { 2015) }\end{array}$ & $\begin{array}{l}\text { Asynchronous } \\
\text { MAC with one } \\
\text { radio }\end{array}$ & $\begin{array}{l}\text { End-to-end transmission delay } \\
\text { and overhearing }\end{array}$ & $\begin{array}{l}\text { Reduces energy consumption, } \\
\text { end-to-end delay and packet loss } \\
\text { compared with SW-MAC }\end{array}$ & $\begin{array}{l}\text { Multi-hop WSNs } \\
\text { with dynamic traffic } \\
\text { loads }\end{array}$ \\
\hline $\begin{array}{l}\text { TAS-MAC (Liu } \\
\text { et al., 2016) }\end{array}$ & Synchronous MAC & $\begin{array}{l}\text { Low channel utilisation } \\
\text { problem in TDMA, } \\
\text { overhearing, idle listening and } \\
\text { latency }\end{array}$ & $\begin{array}{l}\text { Improves throughput as compared } \\
\text { with Z-MAC and DW-MAC } \\
\text { without sacrificing energy } \\
\text { efficiency }\end{array}$ & $\begin{array}{l}\text { Static WSNs with } \\
\text { bursty traffic } \\
\text { (multi-hop) }\end{array}$ \\
\hline $\begin{array}{l}\text { AS2-MAC } \\
\text { (Anchora et al., } \\
\text { 2016) }\end{array}$ & Synchronous MAC & $\begin{array}{l}\text { Collision, idle listening, } \\
\text { over-emitting and overhearing }\end{array}$ & $\begin{array}{l}\text { Shows better performance in terms } \\
\text { of energy efficiency and packet } \\
\text { delivery ratio as compared with } \\
\text { Zigbee standard MAC }\end{array}$ & $\begin{array}{l}\text { Environment } \\
\text { monitoring } \\
\text { (multi-hop) }\end{array}$ \\
\hline $\begin{array}{l}\text { FAWR } \\
\text { (Pegatoquet } \\
\text { et al., 2019) }\end{array}$ & $\begin{array}{l}\text { Asynchronous } \\
\text { MAC with WuR }\end{array}$ & $\begin{array}{l}\text { Energy consumption, latency } \\
\text { and collisions for EH-WSNs }\end{array}$ & $\begin{array}{l}\text { Outperforms the state-of-the-art } \\
\text { duty-cycled MAC protocols in } \\
\text { terms of energy consumption, } \\
\text { transmission latency and collision } \\
\text { rate }\end{array}$ & $\begin{array}{l}\text { Energy harvesting } \\
\text { based monitoring } \\
\text { applications } \\
\text { (multi-hop) }\end{array}$ \\
\hline
\end{tabular}

is proposed in Du et al. (2007). R-MAC uses cross-layer routing information to reduce latency and improve contention handling without limiting energy efficiency and throughput. In R-MAC, a series of control frames, namely PIONs (Pioneer frames), is used across multiple hops instead of RTS/CTS frames in S-MAC. Similar to the RTS/CTS frame, a PION requests for communication and waits for confirmation. Moreover, it adds cross-layer information, including the final destination address of the traffic and the hop counts. Other than the final destination address, PION also carries its own address and the previous/next-hop addresses. When a transmitter has data to transmit, the transmitter first waits for a random period of time chosen from a contention window followed by DIFS before transmitting a PION frame to the next-hop node. RMAC control behaviour is shown in Figure 5 in which node $\mathrm{S}$ is the transmitter. As seen in the figure, when A receives the source node's (S) PION, it obtains the next-hop address from its network layer and waits for a duration of SIFS before sending its PION frame to the next hop. This PION frame (from A) works as an RTS frame to the next hop (B) and as a CTS frame to the source node (S). This dual function of PION frame makes RMAC very efficient in delivering data using multi-hops in a single cycle. On receiving A's PION frame, B repeats the same steps as $\mathrm{A}$, and this process continues until the final destination is reached or the current DATA period is finished.

In spite of the potentials offered by R-MAC, there are some limitations with the practical implementation of R-MAC in WSN since the PION mechanism introduces additional complexity in handling packets.
Figure 5 R-MAC control behaviour (see online version for colours)

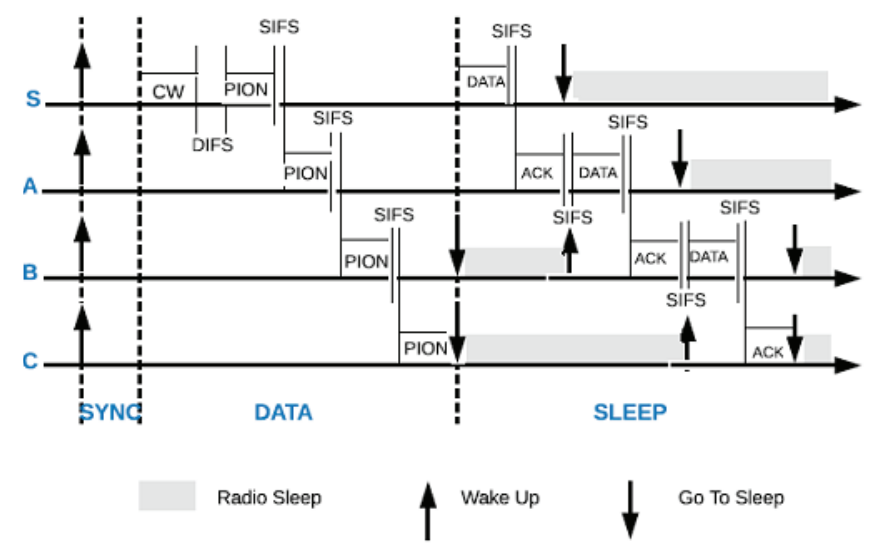

\section{TAS-MAC}

In Liu et al. (2016), a low-power, low-duty cycle, trafficadaptive synchronous MAC protocol named TAS-MAC is proposed to achieve low delay and high throughput with low energy consumption. In WSN MAC protocol design, though duty cycling reduces energy consumption, it restricts throughput and enhances end-to-end latency. High throughput can be supported by TDMA-based schemes where multiple contending nodes have data to transmit. However, TDMA offers low channel utilisation when there are only a few nodes to contend the medium. One solution to overcome this drawback is to use the slot-stealing technique proposed in Gobriel et al. (2009) and Rhee et al. (2008), in which a slot 
abandoned by its owner can be used by other contending nodes. However, this method introduces additional idle listening and overhearing and thereby deviates from the goal of achieving low power consumption. In contrast to the prior work, TAS-MAC tries to address the underutilisation problem by allocating time slots only to those contending nodes, which are on active routes. This ensures high throughput. TAS-MAC achieves low end-to-end delay by notifying all active-route nodes about incoming data traffic in advance. The traffic adaptive feature is addressed by splitting traffic notification and data transmission scheduling into two phases. In the traffic notification phase, the notification packets are transmitted in pulse-mode to ensure fast traffic notification. In the data transmission scheduling phase, time slots are allocated to active-route nodes based on their traffic loads. All other nodes can remain in sleep state, which in turn improves channel utilisation without compromising energy efficiency. TASMAC can provide better throughput as compared with Z-MAC and DW-MAC, and shows the similar delay performance of slot-stealing assisted TDMA schemes while ensuring lower energy consumption.

\section{$A S 2-M A C$}

In Anchora et al. (2016), an IEEE 802.15.4 compatible, synchronous duty cycling MAC protocol named AS2-MAC is proposed. AS2-MAC aims to reduce energy consumption in WSNs using smart awake approach. With AS2-MAC, during the initial network set-up phase, each node builds a map of its neighbours containing the information of their wakeup periods. In the wake-up table, there is an entry for each neighbouring node. In the receiving phase, each node uses the collected information stored in the wake-up table to turn on its radio only when it has data to transmit or receive to/from its neighbours. This approach minimises a node's unnecessary wake-up and hence is able to reduce energy consumption. AS2-MAC exploits a low power mode of MAC, namely coordinated sampled listening (CSL), to periodically check if there is any incoming transmission on the channel. As compared with ZigBee standard MAC protocol, AS2-MAC shows better performance in terms of energy efficiency and packet delivery ratio if the chosen packet rate is consistent with the bandwidth of IEEE 802.15.4 networks and if the duty cycle and the transmission power are selected appropriately based on the traffic loads.

\subsection{Asynchronous MAC protocols}

Synchronous duty cycling MAC protocols incur synchronisation overhead and drain a considerable amount of power even in the absence of network traffic. On the contrary, asynchronous MAC protocols eliminate synchronisation overhead as each node can select its own active schedule without the need to get synchronised with neighbours' schedules. Asynchronous approaches can support ultra-low duty cycle provided an efficient mechanism is implemented to establish data communication between the source and the target. These mechanisms can be sender-initiated or receiver-initiated. With the sender-initiated mechanism, asynchronous protocols mainly use preambles to wake-up the target receiver. When a sender has data in the queue, it first sends a preamble signal to notify the receiver that it has data to transmit. The preamble needs to be long enough so that all potential receivers can detect it. However, the long preamble introduces the overhearing problem and hence causes energy consumption for non-target nodes. This problem can be solved by dividing the long preamble into short pulses. With the receiver-initiated mechanism, the receiver sends a short frame named beacon to notify when to initiate transmission (Cano et al., 2011; Carrano et al., 2014). Since a wake-up beacon is shorter than a preamble, collisions and bandwidth utilisation are reduced with receiver-initiated approaches (Sun et al., 2008).

Asynchronous MAC protocols can be subdivided into two subclasses: MAC with one radio and MAC with WuR. A number of asynchronous MAC protocols, namely STEM, BMAC, WiseMAC, RATE-EST, X-MAC, RI-MAC, C-MAC, DC-MAC, PW-MAC, SA-RI-MAC, DCW-MAC, AS-MAC, WX-MAC, SW-MAC, TR-MAC, DS-MAC, and FAWR, are proposed in the literature that eliminate synchronisation overhead. All of these asynchronous MAC protocols except STEM, RATE-EST, DC-MAC, DCW-MAC, and FAWR are classified as MAC with one radio. STEM, RATE-EST, DCMAC, DCW-MAC, and FAWR are MAC protocols with WuR. In this subsection, each of these MAC protocols is summarised as below.

\section{STEM}

Sparse topology and energy management (STEM) is proposed in Schurgers et al. (2002). It is a multi-hop protocol. It uses separate channels for the main radio and the WuR, thereby avoiding interference between wake-up message and data. Based on the format of the wake-up message, STEM has two variants: STEM-B and STEM-T. In STEM-B, when a node wants to transmit data, it begins sending wake-up beacons containing the transmitter and receiver MAC addresses till a beacon gets an acknowledgement (ACK) from the targeted radio. After receiving an $\mathrm{ACK}$, the sender and the receiver turn on their main radios for data transmission. At the same time, WuR periodically checks the presence of wake-up messages from other nodes. When a collision happens on the wake-up channel, the sensor nodes sensing it wake up their main radios without transmitting back any ACK. As the initiating node does not get the ACK from the target node, it initiates sending data in the following cycle. After a certain period of time, nodes that are not targeted for data communication switch back to the monitoring state while the target node still keeps its main radio on to receive data. STEM-T simplifies the wakeup procedure. In STEM-T, a simple tone is transmitted rather than transmitting a beacon with addresses. The rest procedure for data communication with collision incidents is the same as before.

One drawback of STEM-T is that a simple tone wakes up all the neighbouring nodes. Thus, power consumption is increased. Another limitation is, as the wake-up ACK is removed, the sender has to send the wake-up tone for a significant amount of time. Thus, the delay is increased. 


\section{$B-M A C$}

B-MAC, proposed in Polastre et al. (2004), is an asynchronous CSMA protocol that aims to provide high channel utilisation, collision avoidance, and low power operation. B-MAC exploits an adaptive preamble-sampling mechanism to shorten duty cycle and idle listening, and be tolerant to changing network conditions. Dissimilar to S-MAC, B-MAC uses clear channel assessment (CCA) and backoffs for channel arbitration. In B-MAC, CCA is used to check if there is any activity in the medium during which a node enters into low power listening (LPL) mode. When a node wakes up, it listens to the long preamble to determine whether it needs to remain awake or go to sleep. In this way, a significant amount of energy is saved.

Figure 6 B-MAC overview; node A is transmitting data to node B. Image is redrawn from one that originally appeared in Quintero et al. (2019) (see online version for colours)

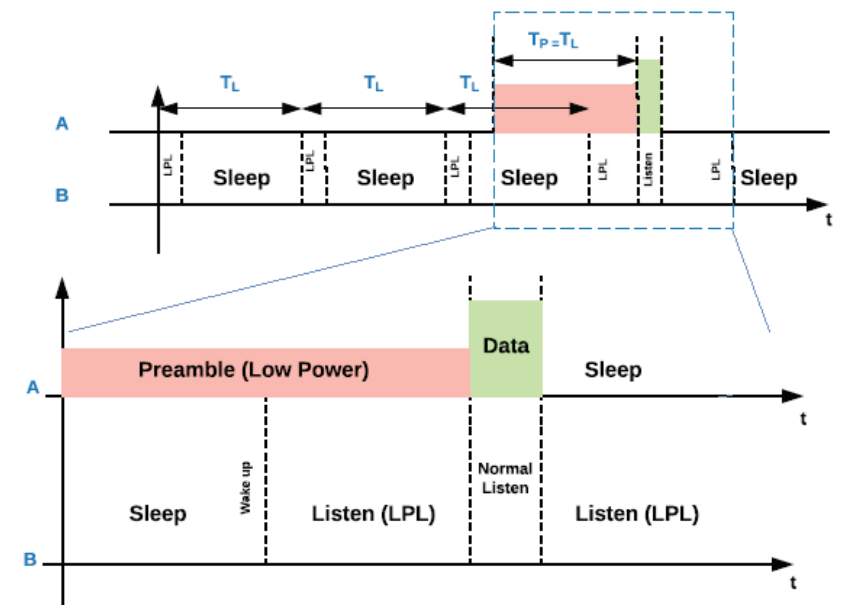

B-MAC's control behaviour is shown in Figure 6. The receiving node periodically listens in LPL mode. The sender stays silent till it has data to send. Once data arrives, the transmitter sends a low power preamble to notify the receiver that it is ready for data transmission. The preamble length $\left(T_{P}\right)$ and the period $\left(T_{L}\right)$ during which the receiver toggles to LPL mode are kept the same to make sure that the receiver is able to detect the preamble. After preamble transmission, the transmitter transmits its queued data. When the receiver senses the presence of incoming traffic, it enters into the active mode. When the transmitter finishes its transmission, it goes back to sleep, and the receiver enters into LPL mode before switching back to sleep mode to ensure there is no more queued traffic in the channel. Results illustrate that B-MAC's flexibility offers better throughput, packet delivery rates, lower delay, and less energy consumption as compared with S-MAC.

\section{WiseMAC}

In 2005, El-Hoiydi and Decotignie (2005) proposed an Alohabased wireless sensor MAC (WiseMAC) protocol to minimise energy consumption in infrastructure WSNs. WiseMAC is based on preamble sampling method (El-Hoiydi, 2002) ensuring low power consumption in WSNs. With this method, the medium is regularly sampled to check the activity. If the medium is busy, a sensor node keeps listening the medium until it finds the medium idle or till a data frame is received. At the access point, a wake-up preamble, which is initially set to the sampling period, is sent for every data frame to make sure that the receiver is awake when data arrives. The new idea introduced in this protocol is that the data acknowledgement frame sent by the receiver carries the scheduling information of its next wake-up time. Hence, the transmitter learns the schedules of when the receiver will wake up and can schedule its transmission accordingly to shorten the preamble length. This, in turn, reduces the overhearing and the latency. Results show that with low bit rate radio transceivers, WiseMAC achieves lower power consumption as compared with power save mode (PSM) protocol used in IEEE 802.15.4 Zigbee standards and IEEE 802.11.

Though WiseMAC overcomes several issues associated with low power WSNs, one drawback of this protocol is that it does not offer any mechanism through which sensor nodes can adapt to varying traffic conditions (Buettner et al., 2006).

\section{RATE-EST}

A traffic adaptive wake-up MAC protocol named rate estimation MAC (RATE-EST) is proposed in Miller and Vaidya (2004). It is a multi-hop protocol. It tries to adjust the subsequent wake-up time dynamically depending on the rate of packet arrival. In RATE-EST, the main channel is used for transmitting control and data packets, and the wake-up channel is used to wake up neighbouring nodes. Low power consumption is achieved by low duty-cycled wake- up radio. Low duty cycle minimises idle listening, however, enhances the latency to wake-up neighbours. To control the delay, a queue threshold (the maximum number of packets in the senor node's queue) is defined in this protocol. When the queue reaches its threshold, the sensor node's WuR initiates sending busy tones, which make all neighbours within one hop of the transmitter go to full wake-up mode. All full wakeup nodes turn on their main radio and listen to their main channel as long as they receive a filter packet. A filter packet indicates which node should keep its radio on for the reception. The other nodes then go back to sleep to save energy. As this full wake-up mechanism is costly, a triggered wake-up method is introduced herein. The source node calculates its transmission rate of sending data and attempts to schedule a triggered wake-up with its destination $\mathrm{T}$ seconds after its last data transmission. RATE-EST tries to adjust $\mathrm{T}$ dynamically based on the estimated traffic load. The authors tried to find the optimum value of $\mathrm{T}$ (for a given data rate) at which power consumption is minimised.

\section{$X-M A C$}

In Buettner et al. (2006), a low power asynchronous MAC scheme, X-MAC, is proposed. The design goals of this protocol are to achieve energy efficiency, low latency, low overhead, high throughput and applicability across all types of packetising for duty-cycled WSNs. X-MAC tries to achieve these targets by overcoming the problems associated with low power listening (i.e., overhearing, excessive preamble length and incompatibility with packetising radios) via strobed preamble approach. With this approach, X-MAC splits the long preamble into a stream of short preamble packets, each 
of which bearing the target node ID. When a node receives a short preamble packet during its wake-up period, it checks if the target node ID attached with the packet matches with its own ID. If the node is the desired receiver, it stays awake for the upcoming data, whereas it goes back to sleep if it is a non-target receiver. One important feature in $\mathrm{X}$ MAC is that it inserts small pauses between short preamble packets allowing the sender to pause and listen to the medium. During a small pause, the receiving node can send an early acknowledgement packet to the sender. In case a sending node receives an acknowledgement from the target receiver, it ceases transmitting preambles and starts data transmission. In this way, the receiver can shorten the excessive preamble, which in turn reduces energy consumption and per-hop delay. The strobed preamble approach is suitable for all types of packetised radios. Experimental results indicate that X-MAC outperforms traditional low power listening scheme.

\section{$R I-M A C$}

A receiver-initiated asynchronous $\mathrm{MAC}$ protocol named RIMAC is proposed in Sun et al. (2008) to enable receiverinitiated data transmission, which aims to support a wide range of network traffic efficiently. RI-MAC tries to reduce latency by minimising the time during which a transmitter and its intended receiver occupy the channel to exchange data. In RI-MAC, all nodes periodically wake up according to their duty cycle schedules. After waking up, if the receiver finds the medium idle, it sends a short beacon frame to the potential transmitter to notify when to initiate data transmission. Upon receiving the beacon, the transmitter immediately sends its data to the receiver. The transmitting node switches back to sleep after finishing data transmission. In case where the transmitter stays silent even after a beacon transmission, the receiver goes to sleep as well. A pictorial illustration of this process is depicted in Figure 7, where $\mathrm{A}$ is the transmitter and $\mathrm{B}$ is the receiver.

Figure 7 RI-MAC overview (see online version for colours)

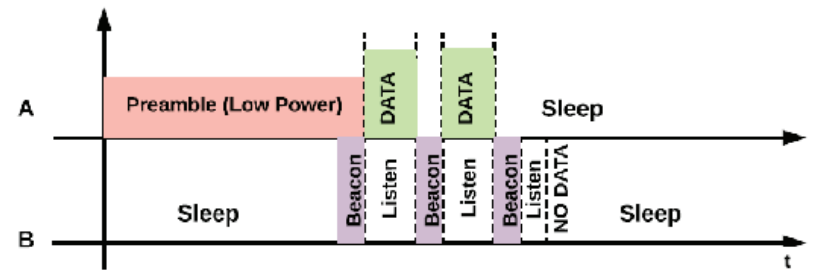

In RI-MAC, as there is no long preamble transmission like LPL-based MAC schemes (B-MAC, for example), and only beacon and data occupy the medium, there remains some room for other nodes for exchanging their data. Simulation results and experiments show that RI-MAC outperforms X-MAC in terms of throughput, energy efficiency, and packet delivery ratio under dynamic traffic loads in WSNs. However, RI-MAC introduces some limitations in the scenario where a transmitter has data to transmit, and it needs to keep its radio on till the intended receiver enters into wake-up mode. Several protocols including PW-MAC are proposed to address this issue.

\section{$P W-M A C$}

Predictive-wakeup MAC (PW-MAC) is proposed in Tang et al. (2011) to minimise energy consumption in WSNs. PW-MAC achieves this by enabling the transmitter to predict the wakeup time of its receiver. PW-MAC transmitter wakes up and switches on its radio just before the receiver enters into wakeup mode. PW-MAC is basically a receiver-initiated MAC protocol that uses a pseudo-random sequence to control the wake-up time of each node, letting the transmitters to predict the wake-up time of its receiver. Hence, PW-MAC is able to reduce the duty cycle for both the transmitter and the receiver. To perform accurate predictions, PW-MAC adopts an on-demand prediction error correction mechanism that tries to correct timing challenges occurred by clock drift, operating system delays and unstable hardware. To secure high energy efficiency, even when collisions occur in the medium, PW-MAC also presents a prediction-based retransmission mechanism. When a sender needs to transmit data to the receiver, it waits for a beacon from the receiver. The receiver wake-up is triggered by a pseudo-random time. The control behaviour of PW-MAC is shown in Figure 8.

Figure 8 PW-MAC overview; A is the transmitter and B is the receiver (see online version for colours)



Results show that in terms of duty cycle, latency and packet delivery ratio, PW-MAC significantly shows better performance as compared with X-MAC, WiseMAC and RIMAC under hidden terminal traffic scenarios as well as under multi-hop traffic flows. PW-MAC has some drawbacks as well. As compared with X-MAC and RI-MAC, PW-MAC causes additional overhead occurred by beacon messages and idle listening.

\section{$C-M A C$}

Low duty cycling technique is very important to enhance network lifetime in WSNs. However, duty cycling MAC protocols have their own limitations. Synchronous duty cycling schemes like S-MAC, T-MAC or D-MAC incur synchronisation overhead and consume considerable power even in the absence of network traffic. On the contrary, asynchronous duty cycling MAC schemes like B-MAC incur high latency in delivering packets because of the lack of synchronisation. To address these issues, Convergent MAC 
(C-MAC) is proposed in Liu et al. (2009) to achieve long network lifetime, low latency and improved throughput.

C-MAC exploits asynchronous sleep scheduling when there is no traffic to transmit. While transmitting traffic, firstly, C-MAC uses anycast to wake up potential forwarders (i.e., forwarding nodes), and then gradually converges from anycast with asynchronous duty cycling to unicast with synchronised scheduling that allows the avoidance of anycast overhead. To reduce the high latency, the long preamble mechanism adopted by B-MAC is replaced by aggressive RTS mechanism in which the long preamble is split up into RTS burst (i.e., RTS packets). To save more power after convergence, a C-MAC variant, namely CMAC-S, is adopted that uses D-MAC-like staggered scheduling after convergence. Simulations and experimental results in Liu et al. (2009) indicate that at low duty cycles CMAC achieves similar latency and throughput performances as CSMA/CA using much lower power. Results also show that C-MAC performs better than B-MAC, D-MAC, S-MAC, and GeRaF (Zorzi and Rao, 2003)protocols in all aspects except for D-MAC in terms of energy consumption.

\section{$D C-M A C$}

A dual channel-based energy-efficient MAC protocol, namely DC-MAC, is proposed in Zheng et al. (2010). It implements a periodic sleeping/listening method along with synchronisation to save energy in multi-hop scenarios. When a node has data to transmit, it activates both radios (i.e., main radio and $\mathrm{WuR}$ ) to do listening. When it finds the channels free, it sends a busy tone to wake up the neighbouring nodes. When the neighbouring nodes that are only one-hop distant to the sender listen the busy tone, they activate their main radios. After that, the best relay nodes (among these neighbouring nodes) are chosen through a mechanism to avoid collision and to minimise the delay. This selection mechanism has three steps:

- $\quad$ deciding the forwarder area

- the calculation of the cost function

- the selection for the best forwarder.

In the first step, the node selects the forwarder area by sending location information of the source and the sink in an RTS frame. Only the nodes, which belong to the data forwarding area, go through the next step. Other nodes turn off their radios. In the next step, the candidate nodes calculate the cost functions based on the channel quality, location information, and the available energy of the candidate. In the last step, each node's priority is calculated. The highest priority node sends its CTS earlier than others. This process is repeated for each hop until the data packet is received by the sink.

DC-MAC aims to reduce latency and save energy by selecting the best next hop toward the destination. However, it introduces additional computational complexity, which consumes energy.

\section{SA-RI-MAC}

In Henna (2011), a RI-MAC based MAC protocol, namely sender-assisted receiver-initiated MAC (SA-RI-MAC), is proposed. SA-RI-MAC combines the receiver-initiated transmission approach of RI-MAC with a sender-assisted contention resolution to adaptively handle the contention among the transmitters for the medium access without sacrificing the energy performance under dynamic traffic load conditions. A sender in SA-RI-MAC waits for a specific beacon from the receiver to start its transmission. While trying to transmit data to the receiver, the sender tracks the number of failures of accessing the channel using a counter named channel access failure (CAF) counter. The value of this counter is exchanged at regular interval among the contending senders using a specific beacon. Prior to data transmission, the contention level at the receiving node is estimated by the sending node using the backoff window size $(\mathrm{BW})$ value defined by the receiver in the beacon. The receiver specifies $\mathrm{BW}$ value as per the contention level at the receiver. The $\mathrm{BW}$ value exceeding the maximum contention window size indicates high contention at the receiver. In high contention scenario, the sender compares its channel access counter value with its neighbouring nodes' counter values. The node which has made more attempts to contact the receiver gets the highest priority to transmit data. In case the sender finds such a contending neighbour, it turns off its radio to minimise energy consumption as well as contention at the receiver. This senderassisted contention resolution enhances fairness among the sending nodes, reduces latency and energy consumption, and provides higher delivery ratio as compared with RI-MAC.

\section{$D C W-M A C$}

DCW-MAC (Mazloum and Edfors, 2011) is an energyefficient MAC protocol that combines ultra-low power wakeup receivers (WRx) with duty-cycled listening to reduce energy consumption. In DCW-MAC, the duty-cycled wakeup receiver, which is controlled by the sleep/listen timer, periodically listens the channel for a wake-up beacon (WB). The main receiver is turned on only when it has data to receive. When a DCW-MAC sender has data to transmit, it switches on its main radio to send out periodic WBs (carrying target's address) to the target. When the wake-up receiver detects the beacon with its ID, it sends back a beacon acknowledgement (BACK). After sending WB, the sender node needs to switch to receive mode to check if there is any BACK. Upon receiving BACK, the sender initiates data transmission. After receiving data, the receiver acknowledges the data by sending DACK. Even though there is some energy consumption associated with sending wake-up beacons and frequent switching between transmit mode and receive mode (for receiving ACK), DCW-MAC shows better energy performance as compared with X-MAC and always-on WRx MAC under low traffic scenario.

\section{$A S-M A C$}

Another energy-efficient WSN MAC protocol, namely ASMAC, is proposed in Jang et al. (2013) to avoid overhearing and minimise latency and contention by asynchronously scheduling the neighbour nodes' wake-up time. One problem associated with preamble-sampling based MAC schemes, such as B-MAC and X-MAC, is overheads. A synchronous scheduled energy-efficient MAC scheme named SCP-MAC (Ye et al., 2006) reduces the preamble by adopting preamble sampling together with scheduling. However, it limits energy 
efficiency due to overhearing and increases delay and contention because of its synchronisation procedure. To address these issues, AS-MAC is proposed for WSNs. Similar to previous schemes, AS-MAC exploits idle listening and LPL to reduce the periodic wake-up time.

With AS-MAC, the sensor nodes minimise the preamble length by storing neighbouring nodes' wake-up schedule. There are two phases in this protocol: initialisation phase followed by periodic listening and sleep phase. In the initialisation phase, a new node, upon joining the network, builds the neighbour table, which stores the scheduling information of its neighbours as well as selects and broadcasts its own distinct offset of periodic wake-up. Existing sensor nodes can be in the initialisation phase or periodic listening and sleep phase. The sensor nodes, which are in periodic listening and sleep phase, execute LPL on every wake-up interval to receive the incoming traffic and transmit Hello packets to announce scheduling information (wake-up interval, Hello interval, and offset) to its neighbours.

The shortcomings of this protocol are the overhead incurred in broadcasting and the requirement of storing onehop neighbour table. Experimental results in Jang et al. (2013) indicate that AS-MAC shows better energy performance as well as reduces delay and packet loss as compared with SCPMAC.

\section{$W X-M A C$}

In Han et al. (2013), another asynchronous MAC protocol is proposed to conserve energy. WX-MAC tries to shorten preamble length at most and keep the sensor nodes in the wake-up state as minimum as possible. In WX-MAC, sensor nodes exchange their sampling schedules via report and query mechanisms. Thus, nodes can estimate the precise time of initiating its preamble using the receiver's sampling schedules. WX-MAC supports strobed preamble approach to halt preamble transmission, start transmitting data and go back to sleep at an appropriate time. It exploits two control messages, namely RTS and CTS, and two report messages, namely neighbour query message (NQM) and neighbour inform message (NIM). Strobed preamble is defined as an RTS sequence. With WX-MAC, sensor nodes broadcast an NQM sequence. The neighbours record the node's sampling schedules and respond with a NIM. The node stores its neighbouring nodes' scheduling information by accumulating NIMs. A node exchange information with an intended neighbour via query mechanism. By using strobed preamble approach and scheduling information of neighbours, WXMAC reduces preamble length prior to data transmission and shortens node's wake-up state. WX-MAC shows better energy performance as compared with B-MAC, WiseMAC and XMAC.

\section{$S W-M A C$}

Sleep window MAC (SW-MAC) (Liang et al., 2014) is an asynchronous MAC protocol, which is designed to reduce packet delivery delay without sacrificing energy performance.

In traditional duty cycling MAC protocol with sleepwake scheduling mechanism, small sleep time results in a significant amount of energy consumption due to idle listening under low traffic loads, whereas too long sleep time causes high latency under high traffic loads. To address this issue, SW-MAC adjusts sleep window adaptively according to the traffic patterns. Furthermore, similar to CMAC, SW-MAC implements a scout-based scheduling mechanism to decrease energy consumption. The receiving node estimates the traffic arrival time and dynamically adapts the sleep time window (employing additive increase/multiplicative decrease (AIMD) scheme) depending on the varying traffic loads.

With SW-MAC, nodes send a sequence of scout packets to wake up the following node. Each node wakes up at regular time interval and listens to the channel to detect a scout packet. When a scout packet is detected, the next hop wakes up and sends an acknowledgement of receiving a scout to the sender. Upon receiving an acknowledgement, the sending node stops sending scouts and starts transmitting the data packet. The receiving node will remain in active state to receive data packets and forward it to the next hop. SWMAC defines node's active time based on the bandwidth of the wireless channel, the length of scout packet, queue length and the number of sending nodes. The sleep time of a node is kept maximum until a packet is received. When a node receives a packet, it decreases the sleep time according to the waiting time of the packet received (estimated from scout packets). The estimated sleep time is utilised to regulate the sleep window. The scout-based scheduling method together with adaptive sleep window approach shortens the end-to-end delivery latency.

\section{TR-MAC}

An adaptive duty cycling asynchronous MAC protocol named TR-MAC is proposed in Morshed and Heijenk (2014) for low data rate WSN applications. Transmitted reference (TR) modulation in the physical layer is a novel scheme using which the transmitters transmit both unmodulated and modulated signal with a known frequency offset, and so consume more energy as compared with traditional modulation scheme. However, with this modulation technique, the receiver can recover the baseband signal quickly by correlating the received signal with its delayed version using the known frequency offset, and consume less power without the need of using rake receiver, CSI (Channel State Information) or energy-hungry oscillators. TR-MAC exploits all the advantages offered by TR modulation while mitigating its drawbacks as well as enables nodes to adjust their duty cycle depending on the energy available in the node.

In TR-MAC, the transmitter first sends a small preamble and then waits (listen) for an acknowledgement from the receiver. This preamble-listen cycle continues until it receives an acknowledgement. Thus, the transmitter can reduce its preamble length, and so can minimise its energy consumption. TR-MAC receiver saves its energy by staying in sleep mode most of the time. The receiver only wakes up to detect activities in the channel. Hence, idle listening is minimised. The control packet overhead is reduced by appending small data packets in the range of very few bytes with a very short preamble. Similar to WiseMAC, the receiver continues listening if there are larger packets followed by the initial small data packets. Besides, TR-MAC avoids collision by addressing multiple 
access issue using frequency offsets. Results indicate that TR-MAC together with TR modulation outperforms X-MAC and WiseMAC protocols in terms of energy efficiency, and minimises the four main sources of energy consumption, namely idle listening, collision, overhearing, and overhead.

\section{$D S-M A C$}

Though asynchronous MAC protocol can reduce overhead, one problem associated with this type of duty cycling protocol is, when a sensor node wakes up to transmit a data packet, it must need to wait until the receiving node wakes up, which in turn introduces the waiting delay. In case of heavy traffic, packet overflow may occur, which eventually produces significant packet loss.

In Wang et al. (2015), an asynchronous MAC protocol named DS-MAC (Demand Sleep MAC) is proposed to alleviate the high end-to-end transmission delay problem under dynamic traffic load conditions. With DS-MAC, the sensor nodes adaptively adjust their sleep time depending on the amount of the received data to ensure efficient data communication under dynamic traffic loads. In DS-MAC, a series of token packets are transmitted to wake up the receiving node that overcomes overhearing problem. A DSMAC sender uses a prediction mechanism to predict the receiver's wake-up time. When a node wants to transmit data, it transmits a series of token packets as long as it receives the acknowledgement packet from the receiver. The duration of transmission between source and target is inserted into token packets. Upon receiving data, the receiver adjusts its sleeping time dynamically based on the amount of received data packet and adds the predicted sleeping time into ACK packets. When the source node receives the ACK, it can predict the next wakeup time of its destination. In this way, the source node can wake up slightly earlier than the target node, thereby decreasing the waiting time and energy consumption.

\section{FAWR}

In Pegatoquet et al. (2019), a multi-hop WuR-based MAC protocol, namely fully asynchronous WuR (FAWR), is proposed for EH-WSNs. FAWR tries to overcome the limited range of existing WuRs via multi-hop relaying mechanism. It enables fully asynchronous communication between a base station and any node within the WSN with low end-to-end delay and high energy efficiency. FAWR reduces collisions by transmitting wake-up calls (WuCs) and data packets using two different data rates.

In FAWR-based WSN architecture, each end device (ED) (powered by energy harvesting system) is equipped with a main radio to transmit data and a WuR to activate nodes on demand. EDs are deployed around a base station. The BTS controls all network operations, including neighbour discovery, data communication or EDs' wake-up interval adaptation. When an end device switches into sleep mode, all modules are turned off except the WuR that consumes a very small amount of power (in few $\mathrm{mw}$ ). WuR is kept in always-on mode to detect $\mathrm{WuC}$. Once a $\mathrm{WuC}$ is detected, an end device switches into active mode and the WuR sends an interrupt signal to turn on the microcontroller unit (MCU). The MCU compares if the destination address is identical with the ED's physical address. If both addresses match, the MCU powers up the main radio to initiate data communication. Otherwise, the MCU is turned off, and the ED goes back to sleep. An ED also needs to wake up when all WuCs from the BTS need to be forwarded to another sensor node. In such situation, an ED acts as a relay node. Each ED supports multi-hop mechanism by maintaining its forwarding decision table (FWT) constructed during network discovery. When the destination address extracted from the WuC matches a table entry of ED's FWT, it needs to wake up to forward the WuC. By exploiting FWT, FAWR reduces the signalling overhead required for forwarding wake-up calls (WuCs) through multiple relay nodes. Results in Pegatoquet et al. (2019) show that FAWR outperforms state-of-the-art duty-cycled MAC protocols in terms of energy consumption, transmission latency and collision rate.

\section{TDMA-based MAC protocols}

TDMA-based MAC protocols are mainly a branch of reservation-based MAC protocols. In TDMA-based MAC, time is divided into frames, each of which is further split into a number of slots. Each sensor node is scheduled with a specific guaranteed time slot using which it can transmit or receive. It turns its radio off at other time slots. Therefore, scheduling-based MAC protocol allows collisionfree transmission and can provide improved throughput, but at the cost of synchronisation overhead. The other problem associated with TDMA-based MAC scheme is that it offers poor channel utilisation when only a few sensor nodes want to transmit data.

TDMA-based MAC protocols can be of two categories: centralised and distributed schemes. In centralised TDMAbased MAC protocol, the base station or cluster heads $(\mathrm{CH})$ allocate time slots to all nodes within the WSN. On the other hand, in the distributed MAC protocol, the slot assignment is not managed by any centralised entity. Instead, the nodes can control their schedules as per local network information. The characteristics of several TDMA-based WSN MAC protocols are discussed below. Table 2 summarises some features of these protocols.

\section{E-TDMA}

In conventional TDMA, energy consumption due to collisions is avoided. However, energy wastage during an idle period cannot be avoided as sensor nodes keep their power on during their scheduled time slots regardless of whether they have any data to transmit or not. This issue is addressed in lowenergy adaptive clustering hierarchy $(\mathrm{LEACH})$ proposed in Heinzelman et al. (2000) that implements an energy-efficient TDMA MAC protocol (E-TDMA) for cluster-based WSNs. In E-TDMA, a source node turns off its radio if it has no data packet to transmit during its allocated time slot, which reduces energy consumption. LEACH operation is divided into rounds. Each round is made of a set-up phase and a steady-state phase. The duration of the steady-state phase is longer than the set-up phase in order to reduce overhead. In the set-up phase, cluster is formed, and in the steady-state phase, data is transmitted 
Table 2 TDMA-based MAC protocols

\begin{tabular}{|c|c|c|c|c|}
\hline Protocols & Protocol type & Issues addressed & Performance & Target applications \\
\hline $\begin{array}{l}\text { E-TDMA } \\
\text { (Heinzelman } \\
\text { et al., 2000) }\end{array}$ & $\begin{array}{l}\text { Scheduling- } \\
\text { based } \\
\text { MAC }\end{array}$ & $\begin{array}{l}\text { Collisions, energy consumption } \\
\text { in idle state, overhead, and } \\
\text { network lifetime }\end{array}$ & $\begin{array}{l}\text { Reduces energy consumption as } \\
\text { compared with conventional TDMA }\end{array}$ & Hierarchical WSNs \\
\hline $\begin{array}{l}\text { PACT (Pei } \\
\text { and Chien, } \\
\text { 2001) }\end{array}$ & $\begin{array}{l}\text { Scheduling- } \\
\text { based } \\
\text { MAC }\end{array}$ & $\begin{array}{l}\text { Energy conservation, overhead, } \\
\text { supporting any routing protocol } \\
\text { and any network topology }\end{array}$ & $\begin{array}{l}\text { Reduces energy consumption, and } \\
\text { improves the lifetime of the network by } \\
5 \text { times as compared IEEE } 802.11\end{array}$ & $\begin{array}{l}\text { Battle field } \\
\text { surveillance, space } \\
\text { exploration and } \\
\text { monitoring } \\
\text { (multi-hop) }\end{array}$ \\
\hline $\begin{array}{l}\text { E-MAC } \\
\text { (van Hoesel } \\
\text { et al., 2004) }\end{array}$ & $\begin{array}{l}\text { Scheduling- } \\
\text { based } \\
\text { MAC }\end{array}$ & $\begin{array}{l}\text { Network lifetime, collision, } \\
\text { and overhead }\end{array}$ & $\begin{array}{l}\text { Prolongs network lifetime (compared } \\
\text { with S-MAC), particularly in networks } \\
\text { with dynamic topology }\end{array}$ & $\begin{array}{l}\text { Static and dynamic } \\
\text { WSNs (multi-hop) }\end{array}$ \\
\hline $\begin{array}{l}\text { BMA }(\mathrm{Li} \\
\text { and } \\
\text { Lazarou, } \\
\text { 2004) }\end{array}$ & $\begin{array}{l}\text { Scheduling- } \\
\text { based } \\
\text { MAC }\end{array}$ & $\begin{array}{l}\text { Energy consumption due to } \\
\text { idle listening and collisions, } \\
\text { and latency }\end{array}$ & $\begin{array}{l}\text { Shows better energy performance in } \\
\text { low and medium traffic scenarios as } \\
\text { compared with conventional TDMA } \\
\text { and E-TDMA }\end{array}$ & $\begin{array}{l}\text { Event-driven } \\
\text { applications }\end{array}$ \\
\hline $\begin{array}{l}\text { DEE-MAC } \\
\text { (Cho et al., } \\
\text { 2005) }\end{array}$ & $\begin{array}{l}\text { Scheduling- } \\
\text { based } \\
\text { MAC }\end{array}$ & $\begin{array}{l}\text { Energy consumption due to } \\
\text { idle listening }\end{array}$ & $\begin{array}{l}\text { Shows better energy efficiency } \\
\text { compared with S-MAC }\end{array}$ & $\begin{array}{l}\text { Event-driven } \\
\text { applications }\end{array}$ \\
\hline $\begin{array}{l}\text { TRAMA } \\
\text { (Rajendran } \\
\text { et al., 2006) }\end{array}$ & $\begin{array}{l}\text { Scheduling- } \\
\text { based } \\
\text { MAC }\end{array}$ & $\begin{array}{l}\text { Collisions, throughput, latency, } \\
\text { and fairness }\end{array}$ & $\begin{array}{l}\text { Achieves better energy efficiency } \\
\text { compared with CSMA, S-MAC and } \\
\text { NAMA }\end{array}$ & $\begin{array}{l}\text { Periodic data } \\
\text { collection and } \\
\text { monitoring }\end{array}$ \\
\hline $\begin{array}{l}\text { Y-MAC } \\
\text { (Kim et al., } \\
2008 \text { ) }\end{array}$ & $\begin{array}{l}\text { Scheduling- } \\
\text { based } \\
\text { MAC }\end{array}$ & $\begin{array}{l}\text { Throughput, energy } \\
\text { consumption under diverse } \\
\text { traffic conditions }\end{array}$ & $\begin{array}{l}\text { Shows high performance with low } \\
\text { power consumption }\end{array}$ & $\begin{array}{l}\text { WSNs under high } \\
\text { traffic conditions }\end{array}$ \\
\hline $\begin{array}{l}\text { TreeMAC } \\
\text { (Song } \\
\text { et al., 2009) }\end{array}$ & $\begin{array}{l}\text { Scheduling- } \\
\text { based } \\
\text { MAC }\end{array}$ & $\begin{array}{l}\text { Throughput, congestion and } \\
\text { energy conservation }\end{array}$ & $\begin{array}{l}\text { Outperforms CSMA and } \\
\text { Funneling-MAC in terms of throughput } \\
\text { and energy efficiency }\end{array}$ & $\begin{array}{l}\text { Real-time high data } \\
\text { rate WSNs } \\
\text { (multi-hop) }\end{array}$ \\
\hline $\begin{array}{l}\text { S-TDMA } \\
\text { (Boulfekhar } \\
\text { et al., 2012) }\end{array}$ & $\begin{array}{l}\text { Scheduling- } \\
\text { based } \\
\text { MAC }\end{array}$ & $\begin{array}{l}\text { Idle listening, collisions and } \\
\text { overhearing }\end{array}$ & $\begin{array}{l}\text { Outperforms LEACH in terms of } \\
\text { energy efficiency, latency and packet } \\
\text { delivery ratio }\end{array}$ & Static WSNs \\
\hline $\begin{array}{l}\text { E-BMA } \\
\text { (Shafiullah } \\
\text { et al., 2013) }\end{array}$ & $\begin{array}{l}\text { Scheduling- } \\
\text { based } \\
\text { MAC }\end{array}$ & Energy preservation & $\begin{array}{l}\text { Outperforms conventional TDMA and } \\
\text { BMA in all traffic conditions }\end{array}$ & $\begin{array}{l}\text { Railway-wagon } \\
\text { monitoring }\end{array}$ \\
\hline $\begin{array}{l}\text { BS-MAC } \\
\text { (Alvi et al., } \\
\text { 2015) }\end{array}$ & $\begin{array}{l}\text { Scheduling- } \\
\text { based } \\
\text { MAC }\end{array}$ & $\begin{array}{l}\text { Energy consumption due to } \\
\text { control overheads, average } \\
\text { packet delay, throughput, and } \\
\text { efficient handling of adaptive } \\
\text { traffic loads }\end{array}$ & $\begin{array}{l}\text { Improves energy efficiency and } \\
\text { throughput, and reduces delay } \\
\text { compared with E-TDMA and } \\
\text { BMA-RR }\end{array}$ & $\begin{array}{l}\text { Hierarchical WSNs } \\
\text { with adaptive traffic }\end{array}$ \\
\hline $\begin{array}{l}\text { DS-MMAC } \\
\text { (Sreejith } \\
\text { and } \\
\text { Gudino, } \\
\text { 2016) }\end{array}$ & $\begin{array}{l}\text { Scheduling- } \\
\text { based } \\
\text { MAC }\end{array}$ & Overhead and collisions & $\begin{array}{l}\text { Provides better energy efficiency, data } \\
\text { rate and reduces control overhead }\end{array}$ & Mobile WSNs \\
\hline $\begin{array}{l}\text { EH-TDMA } \\
\text { (Kosunalp, } \\
\text { 2016) }\end{array}$ & $\begin{array}{l}\text { Scheduling- } \\
\text { based } \\
\text { MAC }\end{array}$ & $\begin{array}{l}\text { Network lifetime and } \\
\text { throughput }\end{array}$ & $\begin{array}{l}\text { Shows better performance in terms of } \\
\text { energy efficiency and throughput as } \\
\text { compared with ID-polling }\end{array}$ & $\begin{array}{l}\text { Energy-harvesting } \\
\text { WSNs }\end{array}$ \\
\hline $\begin{array}{l}\text { BEST- } \\
\text { MAC (Alvi } \\
\text { et al., 2016) }\end{array}$ & $\begin{array}{l}\text { Scheduling- } \\
\text { based } \\
\text { MAC }\end{array}$ & $\begin{array}{l}\text { Energy consumption due to } \\
\text { control overheads, delay, } \\
\text { scalability, efficient handling of } \\
\text { adaptive data traffic, and link } \\
\text { utilisation }\end{array}$ & $\begin{array}{l}\text { Able to transmit more data with } \\
\text { reduced energy consumption and } \\
\text { latency as compared with E-TDMA } \\
\text { and BMA-RR }\end{array}$ & $\begin{array}{l}\text { Smart city } \\
\text { applications }\end{array}$ \\
\hline
\end{tabular}

to the base station. At the beginning of the cluster formation phase, the cluster head $(\mathrm{CH})$ needs to be selected based on the stochastic algorithm. Each member node has to decide whether it can be a $\mathrm{CH}$ for this round depending on the desired percentage of $\mathrm{CHs}$ for the network and the statistics of how many times the sensor node has been a $\mathrm{CH}$ as yet. Each elected $\mathrm{CH}$ broadcasts an advertisement message, $\mathrm{CH} \_\mathrm{ANN}$, to the remaining nodes. All non-CH nodes need to keep their radio on during this advertisement phase to listen to $\mathrm{CH} \_$ANN. After the advertisement phase, depending on the received signal strength of the $\mathrm{CH}$ _ANN, each non-CH node has to decide which cluster it will belong to for current round. After making decision, each node informs the chosen $\mathrm{CH}$ that it will be a cluster member. The $\mathrm{CH}$ receives all the messages from the 
nodes intended to be the member of the cluster and makes a TDMA schedule for all member nodes. The $\mathrm{CH}$ broadcasts this schedule to all member nodes within the cluster. The nodes can transmit data during their allocated time slot to the $\mathrm{CH}$. After gathering all the data, the $\mathrm{CH}$ processes the data and send it to the base station.

Both TDMA and E-TDMA are not able to handle adaptive traffics since they uniformly allocate time slots among all member nodes within the cluster (Alvi et al., 2016; Kaur and Kumar, 2016).

\section{PACT}

An energy-efficient TDMA-based MAC protocol, namely power aware clustered TDMA (PACT), is proposed in Pei and Chien (2001). PACT tries to exploit passive clustering to prolong the network lifetime. In passive clustering, individual energy levels of all nodes are considered, and cluster heads are selected based on nodes' leftover battery lifetime. Though cluster head selection is made depending on the energy level of the battery, the role of gateways and cluster heads is rotated to save energy.

In PACT, each time frame consists of control slots and data slots. During control slots, all sensor nodes switch on their radio. Each node announces its data slot allocation information to the neighbouring nodes using its scheduled control slot. All nodes learn about the status of data slot assignment from the control packets and select non-conflicting allocations for its transmission. Cluster heads and gateways have a higher priority in selecting its slots. Each ordinary node can select its slots only after the neighbouring cluster heads and gateways have obtained their required slots.

Compared with contention-based MAC protocol, PACT provides a greater reduction in idle energy dissipation by turning off the radio during idle slots. However, as it uses clustering, some amount of overhead is there.

\section{E-MAC}

A distributed and self-organising TDMA-based MAC protocol named E-MAC (EYES MAC) is proposed in van Hoesel et al. (2004) to prolong network lifetime both in static and dynamic networks. In E-MAC, nodes can be in three different operating modes, namely active, passive and dormant mode. An active node can forward messages to a destination and receive data from passive nodes. A passive node can preserve energy by only keeping track of control messages of the chosen active node. The dormant nodes stay in a low-power state for a fixed amount of time or when they are running out of power and need to be recharged using ambient energy.

In E-MAC, each node is assigned with only one time slot in each frame. The time slots are not assigned by a central manager or base station. Instead, sensor nodes can pick their time slots autonomously using local network knowledge. Each time slot is divided into three parts: communication request (CR), traffic control (TC) and DATA. During the CR period, other sensor nodes can file their request to the current owner of a time slot. Nodes with no request go to the lowpower state during the CR section. As seen from Figure 9, an active node first listens for the incoming requests from passive nodes for CR duration in its time slot. After that, the node sends a control message during the TC section containing a possible acknowledgement to the request as well as other synchronisation and control information. All neighbouring nodes within 1-hop distance listen to the TC message. The last fraction of time in a time slot is the DATA section, which can be used for data transfer from the upper layers.

Results in van Hoesel et al. (2004) show that as compared with SMAC, E-MAC prolongs network lifetime with a factor of 2.2-2.7 in static networks and with a factor of 2.9-4.2 in dynamic networks. However, EMAC does not provide good performance in high traffic scenario.

Figure 9 E-MAC (see online version for colours)

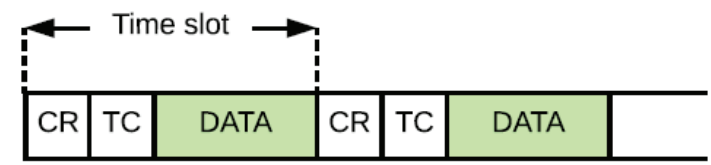

\section{$B M A$}

Another TDMA-based MAC protocol named bit-map-assisted MAC (BMA) is proposed in Li and Lazarou (2004) for large scale cluster-based WSNs. It is designed for event-driven WSN applications, where nodes send the data packet to the cluster head only if particular events are detected. BMA aims to reduce energy wastages occurred due to collisions and idle listening while providing a good network performance in terms of latency.

BMA operation is split into rounds, where each round is comprised of two phases: cluster set-up phase and steadystate phase (as seen in Figure 10). Similar to LEACH, in the cluster set-up phase, a cluster is formed in which a node having the highest energy level is elected as a $\mathrm{CH}$. Elected $\mathrm{CHs}$ broadcast a message to all non- $\mathrm{CH}$ nodes announcing to be the new $\mathrm{CHs}$. Next, all non- $\mathrm{CH}$ nodes join the cluster. Once the cluster is formed, the system goes into the next phase i.e., the steady-state phase. The steady-state phase is split into a number of sessions, each of which is of fixed duration. Each session is divided into three time periods: the contention period consisting of a number of time slots (fixed), the data transmission period (variable) and an idle period. For a cluster, the number of slots is equal to the number of non- $\mathrm{CH}$ sensor nodes. As not all nodes always have to transmit, the data transmission period may vary. However, for each session, the summation of the data transmission period and the idle period is fixed. During the contention period of each session, all sensor nodes keep their power on; and based on a TDMA schedule, each node is allocated with a time slot through which it sends a 1-bit control message if it has data to send. If a node has no data to transmit, its assigned time slot remains empty. Once the contention period is over, the $\mathrm{CH}$ knows which source nodes have data in their queue. The $\mathrm{CH}$ then broadcast a transmission schedule only to the source nodes. During the data transmission period, all source nodes turn on their radios and transmit their data to the $\mathrm{CH}$ over the allocated data slots. If no non- $\mathrm{CH}$ nodes have queued data, the system directly enters into an idle period that persists till the beginning of the following session. When a session is completed, the next session starts following the same procedure. The $\mathrm{CH}$ gathers 
the data from all sources and then forward it to the base station. The system starts the next round after a predefined time period, and the same procedure is repeated.

Figure 10 A single round in BMA operation (see online version for colours)

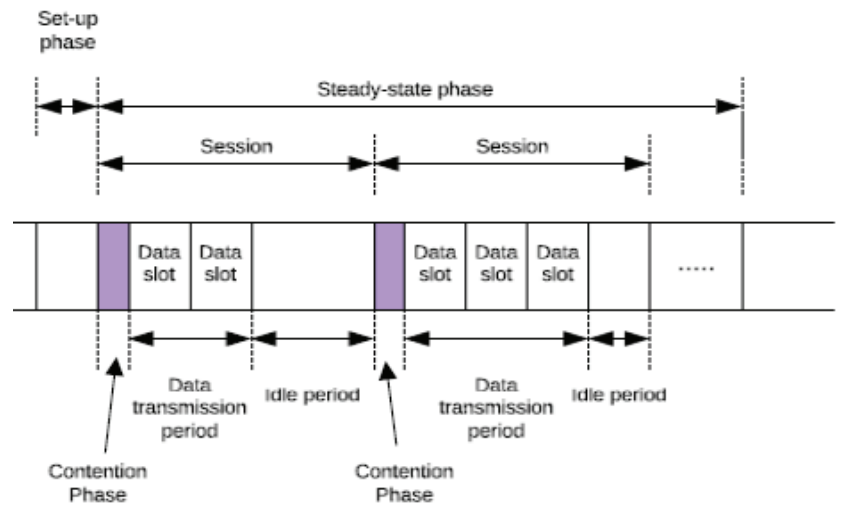

In TDMA, when a source node is scheduled with a data slot, that schedule remains same for all frames in that round irrespective of whether a node has much data to transmit in each frame or not. However, BMA allocates slots in the contention phase prior to the beginning of each frame. Therefore, as compared with conventional TDMA and ETDMA, BMA shows superior performance in terms of energy efficiency in low and medium traffic scenarios with few nodes per cluster and relatively large packet sizes. BMA also provide superior average packet delay performance.

In BMA, though the contention phase tries to reduce the idle listening in the data transmission phase, it itself introduces some energy consumption prior to each frame transmission. At high traffic condition, this contention phase, therefore, becomes an overhead since the data transmission probability is almost definite.

\section{$D E E-M A C$}

In Cho et al. (2005), another TDMA-based MAC protocol, namely dynamic energy efficient-MAC (DEE-MAC), is proposed for event-driven WSN applications. DEE-MAC is a cluster-based approach, which is mainly designed to improve energy efficiency by minimising idle listening. With DEEMAC, the cluster is formed dynamically depending on the node's remaining power level. All sensor nodes can compete for the position of cluster head. DEE-MAC operation can be divided into rounds, where each round comprises of two phases: cluster formation phase and transmission phase (as shown in Figure 11). During the cluster formation phase, each node has to check if it can be the cluster-head. For that, each sensor node desiring to become the cluster-head broadcasts a message carrying its own remaining energy-level to all other sensor nodes contending for the same position. A node, which has the highest power-level, is elected as the cluster head, and all other nodes then join the cluster. In each round, a new cluster with a different set of sensor nodes is formed, based on the changes in nodes' power-level and network structure (Czapski, 2006). After the cluster formation phase, the system enters into the second phase, i.e., the transmission phase. This phase is split into a number of sessions. Each session comprises of two sections, namely a contention period and a data transmission period, where the later one is further divided into a number of time slots. During contention period, each node that has data to transmit keeps its power on, and sends an IS (Interest to Send) packet to the cluster head indicating its interest to transmit data. The IS packet can also carry other information such as join or leave message if more node desires to join or leave a cluster after the cluster formation phase. After the contention period, the cluster head has knowledge about the nodes that want to transmit data. With this knowledge, the cluster head constructs a TDMA schedule and broadcasts it in the first time slot to all nodes. Each node with a cluster is allocated with a data slot during each session. The node(s) that has/have data to transmit/receive remain(s) awake, and all other nodes turn their power off. TDMA-based schemes, together with the clustering technique, reduce the cost associated with idle listening in large-scale WSNs.

Figure 11 A single round in DEE-MAC operation (see online version for colours)



DEE-MAC shows better energy efficiency compared with SMAC. However, it does not consider the error possibility in packets during the contention period.

\section{TRAMA}

TRAMA, proposed in Rajendran et al. (2006), is a TDMAbased traffic-adaptive energy-efficient MAC protocol. It is designed to achieve high energy conservation, good throughput, acceptable packet delivery delay and fairness.

In this protocol, the receivers are selected based on the transmission schedules broadcasted by the transmitters. TRAMA allows sensor nodes to exchange their 2-hop neighbourhood information and the schedules that specify the projected receivers of their traffic in sequential order as well as which nodes should send and receive during each slot. This protocol has three components, namely neighbour protocol (NP), schedule exchange protocol (SEP), and adaptive election algorithm (AEA). During the random access period, nodes use NP to transmit 1-hop neighbour information among the neighbours (using signaling time slots) to gain consistent 2-hop topology information across all sensor nodes. SEP is used to exchange traffic-based schedules with neighbouring nodes. A node needs to broadcast its schedule via SEP before initiating actual transmission. The information gained from NP and SEP is used by AEA to select transmitters and receivers to secure collision-free transmission. 
In TRAMA, a single time-slotted channel is used for both signalling transmission (via random access slots) and data transmission (via scheduled-access slots). Nodes, which want to transmit data, request for slots to use in random access period. TRAMA tries to achieve high energy efficiency by ensuring collision-free transmission and by switching nodes to the sleep state when they are inactive. It achieves bandwidth efficiency by re-using unused slots of the selected transmitter. However, TRAMA experiences higher delay compared with contention-based protocols due to its greater percentage of sleeping time. Hence, TRAMA is not suitable for delaysensitive applications (Pal and Chatterjee, 2014).

\section{$Y-M A C$}

An energy-efficient TDMA-based multi-channel MAC protocol named Y-MAC is proposed in Kim et al. (2008). The design goal of this protocol is to ensure both energy efficiency and high performance.

In Y-MAC, time is divided into a number of frames of fixed length. Each frame consists of a unicast period and broadcast period. Each node needs to wake up at the beginning of the broadcast period to transfer broadcast messages. In case of no incoming broadcast message, each node switches off its radio till its own receive time slot arrives to conserve energy. Regarding the unicast message, after receiving a unicast message, the receiver acknowledges the sender about delivery success if the acknowledgement flag was set to request for an acknowledgement. Otherwise, the flag is cleared to minimise overhead. The unicast message may suffer from long waiting time under heavy traffic conditions. To solve this problem, a light-weight channel hopping mechanism is proposed that uses multi-channels to minimise the latency. Results indicate that under light traffic loads, Y-MAC achieves low duty cycle like other low-power MAC schemes, and under diverse traffic conditions, Y-MAC shows high performance while ensuring low power consumption (Kim et al., 2008).

\section{TreeMAC}

TreeMAC (Song et al., 2009) is a TDMA-based MAC protocol designed to maximise throughput and minimise congestion in addition to energy conservation by using data gathering tree structure.

TreeMAC implements frame-slot assignment algorithm to achieve low congestion and high throughput. TreeMAC divides time into cycles. Each time cycle is divided into a number of frames, each of which is further divided into three slots. The frame assignment reduces horizontal 2-hop interference, and the slot assignment reduces vertical 2-hop interference. For a node, at any time slot, at most one sender (including itself) is active in 1-hop neighbourhood. This provides conflict-free packet transmitting or receiving and snooping. The number of time slots allocated to each node is based on its bandwidth demand. A parent node decides its children's frame assignment according to their bandwidth demand and each sensor node estimates its own slot assignment depending on the hop-count to the base station or sink. Each node allocates frames to its children in proportion to its traffic loads, which in turn ensures fairness in terms of flow. For each sensor node, the frame-slot pair allocated to it defines when the node can transmit/receive or sleep. If a time slot is not assigned for transmitting/receiving, a sensor node can turn its radio off to switch to the sleeping state to preserve energy. Tree-MAC shows better throughput and energy performance as compared with Funneling-MAC (Ahn et al., 2006) and CSMA.

\section{S-TDMA}

In Boulfekhar et al. (2012), a TDMA-based energy-efficient MAC protocol named S-TDMA is proposed to maximise network lifetime by reducing major energy wastages such as idle listening, collisions and overhearing. Overhearing is avoided by letting nodes, which are not in the reception period, go to sleep mode. Collisions and idle listening are avoided by using the TDMA technique. Unlike simple TDMA in which the number of communication links and the number of time slots is equal (thereby, requiring unnecessary time slots that increases latency), S-TDMA ensures each node is allocated with a time slot depending on its collected data. In S-TDMA, if a node has no data to transmit, it will not have any time slot, thereby, decreasing latency. Simulation results in Boulfekhar et al. (2012)indicate that S-TDMA outperforms LEACH protocol in terms of energy efficiency and latency and packet delivery ratio.

\section{E-BMA}

E-BMA (Shafiullah et al., 2013) is another energy-efficient MAC protocol, which is designed to provide better energy efficiency for low and medium traffic loads in WSNs. E$\mathrm{BMA}$ reduces the idle time in contention period to improve energy performance. E-BMA is intended for railway-wagon monitoring systems in which data is collected from the nodes positioned inside the railway wagon and sent to the locomotive for further processing to take safety actions.

Similar to BMA, E-BMA operation is broken up into rounds in which each round is made of a set-up phase followed by a steady-state phase. The steady-state phase is further divided into a contention phase and a data transmission phase consisting of one or more frames. During the set-up phase, the cluster is formed. During the contention phase, all non$\mathrm{CH}$ sensor nodes make a reservation for their data slots. Unlike BMA, E-BMA sensor nodes utilise piggybacking to reserve the corresponding data slot instead of transmitting a control message in its scheduled contention slot. In E-BMA, a source node that has data to transmit does not make allocation immediately after the data packet is available. Rather, it buffers its data and waits for one more frame duration to check whether there are any sequential data packets to transmit. In case a source node has sequential data packets to transmit in a number of successive frames, the node makes its reservation once for the first data packet during its assigned contention slot, and the following confirmations will be done via piggybacking. In E-BMA, the source node turns off its radio during the contention phase if it does not have any 1-bit control message to transmit, while in BMA, the transceiver remains idle in similar conditions. This, in turn, lets the E-BMA preserve energy both in low and medium traffic loads. In the data transmission phase, each source node powers on its radio during its reserved data slot and sends its data to the $\mathrm{CH}$. 
E-BMA shows better energy performance compared with conventional TDMA and BMA in all traffic conditions. However, EA-TDMA (Shafiullah et al., 2008) outperforms EBMA in terms of energy efficiency at extremely high traffic loads.

\section{$B S-M A C$}

Bitmap-assisted shortest job first based MAC (BS-MAC) is proposed in Alvi et al. (2015) targeting hierarchical WSNs. The key attributes of BS-MAC include:

- $\quad$ small-sized time slots that are assigned non-uniformly to source nodes as per traffic condition

- $\quad$ slot scheduling using shortest job first (SJF) scheme

- $\quad$ short node address (1 byte) to minimise overheads and improve energy efficiency.

At the beginning of new round, each node checks if it can be the $\mathrm{CH}$ for this round based on a stochastic algorithm. Similar to BMA and E-BMA, during the cluster set-up phase, the highest energy node is selected as $\mathrm{CH}$, and the remaining nodes join the $\mathrm{CH}$ to form a cluster. The $\mathrm{CH}$ broadcasts a $\mathrm{CH}$ _ANN ( $\mathrm{CH}$ Announcement) message to all the member nodes. In response to this message, the sensor nodes send a JOIN_REQ (Join Request) message to the $\mathrm{CH}$. The $\mathrm{CH}$ computes the total count of member nodes by counting the number of JOIN_REQs received. After that, the $\mathrm{CH}$ assigns a control slot to each member node by transmitting CS_ALLOC message. After cluster set-up phase, the system enters into the steady-state phase, which is split into a number of sessions. The steady-state phase comprises of control slots, data slot announcement period and data slots. Each source node sends its DATA_REQ message during its reserved control slots. The members having no data to transmit power off their radio to conserve energy. The $\mathrm{CH}$ stays in receive mode during the whole control period so that it can receive DATA_REQ messages from source nodes. Next, $\mathrm{CH}$ allocates data slots to all source nodes based on SJF algorithm and informs them about their allocation by broadcasting a frame called allocated data slot announcement (ADS_ANN) frame. If a source node wants to transmit a data packet to its neighbour, the node first transmits its packet to $\mathrm{CH}$ during the first session followed by the data transmission from $\mathrm{CH}$ to the receiving node in the subsequent session.

Results in Alvi et al. (2015) indicate that with BS-MAC, more than $70 \%$ and $80 \%$ delay efficiency can be achieved as well as more than $3 \%$ and $17 \%$ data packet can be transmitted as compared with E-TDMA and BMA-RR (Hsu and Yen, 2011) respectively without sacrificing energy efficiency. One shortcoming of BS-MAC is that it does not consider the scalability issue of WSNs used in smart cities. In Alvi et al. (2016), the scalability issue is addressed.

\section{$D S-M M A C$}

The major drawbacks in contention-based MAC algorithms are increased overhead and high probability of collision. To address these, a cluster-based TDMA MAC protocol, DS-MMAC, is proposed in Sreejith and Gudino (2016) considering a scenario where both static and mobile wireless sensor nodes are deployed. DS-MMAC protocol implements dynamic scheduling of time slot to access channel. The main objective of this protocol is to enhance energy efficiency by ensuring the sleep time of mobile nodes is increased, and the number of control packets utilised for data transfer is reduced. The request-reply mechanism used in this protocol improves the reliability of data communication and informs the mobile sensor node about its data slot in the next radio frame. Results in Sreejith and Gudino (2016)show that DS-MMAC outperforms Hybrid MAC in terms of energy efficiency, data rate and control overhead.

\section{EH-TDMA}

In Kosunalp (2016), a TDMA-based MAC protocol named EH-TDMA is proposed for energy-harvesting WSNs. The design goal of EH-TDMA is to achieve better throughput with infinite network lifetime. With EH-TDMA, sensor nodes harvest ambient energy from the environment and store it employing an energy storage component for future use. EHTDMA adopts a repeating frame structure that consists of a number of transmission slots for data communication. Each sensor node is allocated with a time slot in a single frame coordinated by the receiving node. In EH-TDMA, the receiver periodically broadcasts a small control packet named ping to get the nodes synchronised and to indicate the beginning of the frame. To do this, the receiver needs to check if it has enough stored energy to be awake for the duration of the whole frame. The transmitters keep their radio on until they have sufficient energy to receive the ping packet and send a data packet. After receiving the ping packet, the transmitters keep their power on only in their dedicated time slots, which in turn reduces energy consumption due to idle listening. The control behaviour of EH-TDMA is shown in Figure 12 considering there are three transmitters (A, B and C) and a receiver. The three transmitters are preassigned with a specific time slot. At the beginning, the receiver broadcasts the first ping packet, and the transmitter $\mathrm{A}$ and $\mathrm{C}$ receive it and transmit data packets in Slot 1 and Slot 3 respectively. In the second frame, only B is awake and transmits its data packet in its dedicated slot (Slot 2). In the third frame, the receiver broadcasts another ping packet as it has enough power. $\mathrm{A}, \mathrm{B}$ and $\mathrm{C}$ are now in active mode, as all of them have enough stored energy to receive the ping packet and send their data in their allocated time slots.

Figure 12 EH-TDMA overview (see online version for colours)

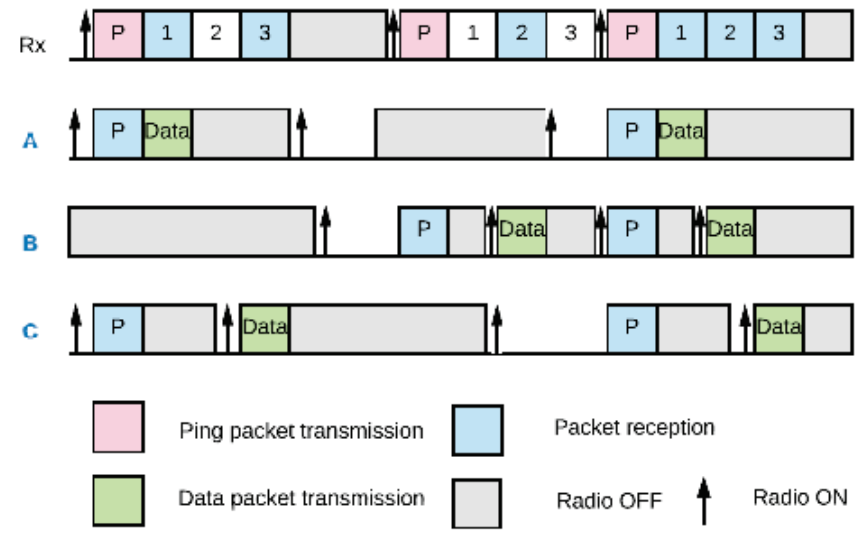


As a collision-free protocol, EH-TDMA does not require the receiver send acknowledgement upon successful reception of the data packet. This saves more energy. Results in Kosunalp (2016) show that EH-TDMA outperforms ID-polling based scheme (more information can be found in Eu et al. (2011)) in terms of energy efficiency and channel throughput in a singlehop scenario. One shortcoming of EH-TDMA is that it does not employ any power management strategy to estimate future energy availability, which is essential for efficient utilisation of the current and future energies.

\section{BEST-MAC}

In Alvi et al. (2016), another TDMA-based MAC protocol, namely BEST-MAC (Bitmap-assisted Efficient and Scalable TDMA-based MAC), is proposed. BEST-MAC is intended for hierarchical WSNs (with diverse traffic), which can be deployed in smart city applications where delay or packet loss is not acceptable. BEST-MAC handles variable traffics of all member nodes by using a large number of tiny time slots and by keeping the number of slots greater than the total number of member nodes. Small slot duration supports efficient data slot allocation based on each source node's requirement. Time slots are allocated following Knapsack algorithm that reduces average packet delay and improves link utilisation. For each member node, BEST-MAC uses short node address ( 1 byte) to minimise network overhead, which in turn reduces energy consumption. BEST-MAC incorporates a contention access period (CAP) in the data transmission phase to accommodate non-member nodes within a network, hence offering scalability.

Similar to BS-MAC, the communication round in BESTMAC is divided into two phases: a set-up phase and a steadystate phase. However, BEST-MAC steady-state phase consists of one additional period, CAP (as seen in Figure 13) i.e., the steady-state phase comprises of four sections: control period (CP), CAP, ADS_ANN message and data slots. In $\mathrm{CP}$, all source nodes need to send data request using their scheduled control slots. In CAP, the non-member nodes can be a member of the network by sending JOIN_REQ message to the control head. The nodes whose join request has been approved are informed via the following ADS_ANN message. During ADS_ANN message period, all member nodes listen to this message to get synchronised with the $\mathrm{CH}$ and informed about some necessary information such as the list of new members joined the network, the list of all source nodes allocated with data slots to send their data packets, and the starting point of the CP. For data slot scheduling, BEST-MAC prioritises source nodes based on the Knapsack optimisation algorithm, whereas BS-MAC uses SJF.

BEST-MAC is able to transmit more data with reduced energy consumption and latency as compared with E-TDMA and BMA-RR (Hsu and Yen, 2011).
Figure 13 A single round in BEST-MAC operation (see online version for colours)



\section{Hybrid MAC protocols}

Hybrid MAC protocols try to combine the strengths of CSMA and TDMA-based MAC protocols while offsetting their limitations. Several hybrid protocols are briefly discussed as below. Table 3 summarises some features of considered hybrid protocols.

\section{Z-MAC}

A hybrid MAC protocol named Z-MAC is proposed in Rhee et al. (2008) for WSNs. Similar to TDMA, Z-MAC can provide good channel utilisation under high contention as well as minimise collisions among 2-hop neighbour nodes at a low cost, and similar to CSMA, it is able to offer good channel utilisation and low end-to-end delay under low contention. Dissimilar to traditional TDMA approach, Z-MAC allows one sensor node to use the slot allocated to others though the owner gets higher priority over non-owners so as the possible collisions can be avoided. Z-MAC exploits CSMA as the baseline MAC protocol and implements a TDMA schedule to improve contention resolution.

Z-MAC control behaviour includes a sequence of operations, namely neighbour discovery and time slot assignment, local framing, and global time synchronisation. In neighbour discovery and time slot assignment, when a sensor node starts up, it first executes a neighbour discovery process to build its 1-hop neighbour list. A node periodically sends a ping to its 1-hop neighbouring nodes to constitute its 1-hop neighbour list. As the process continues, each node can gather its 2-hop neighbour list using the information obtained from the pings from its 1-hop neighbouring nodes. This 2-hop neighbour list is then utilised as an input to the slot assignment scheme. Z-MAC implements a distributed randomised slot assignment algorithm, namely DRAND, for time slot allocation to each node. DRAND ensures that no multiple nodes within a 2-hop neighbour list are scheduled with the same slot to prevent interference. Once slot allocation 
Table 3 Hybrid MAC protocols

\begin{tabular}{|c|c|c|c|c|}
\hline Protocols & Protocol type & Issues addressed & Performance & Target applications \\
\hline $\begin{array}{l}\text { Z-MAC (Rhee } \\
\text { et al., 2008) }\end{array}$ & $\begin{array}{l}\text { Combination of } \\
\text { CSMA and TDMA }\end{array}$ & $\begin{array}{l}\text { Channel utilisation, } \\
\text { latency, and collisions }\end{array}$ & $\begin{array}{l}\text { Behaves like CSMA under low } \\
\text { contention and like TDMA } \\
\text { under high contention }\end{array}$ & $\begin{array}{l}\text { WSNs with expected data } \\
\text { rate and 2-hop contention are } \\
\text { medium to high }\end{array}$ \\
\hline $\begin{array}{l}\text { Adaptive } \\
\text { CSMA/TDMA } \\
\text { (Gilani et al., } \\
\text { 2013) }\end{array}$ & $\begin{array}{l}\text { Combination of } \\
\text { CSMA and TDMA }\end{array}$ & $\begin{array}{l}\text { Energy consumption, } \\
\text { collisions, and throughput } \\
\text { of the IEEE 802.15.4 MAC }\end{array}$ & $\begin{array}{l}\text { Reduces energy consumption } \\
\text { and improves throughput as } \\
\text { compared with IEEE 802.15.4 } \\
\text { MAC. }\end{array}$ & WSNs with high traffic loads \\
\hline $\begin{array}{l}\text { IH-MAC } \\
\text { (Arifuzzaman } \\
\text { et al., 2013) }\end{array}$ & $\begin{array}{l}\text { Combination of } \\
\text { CSMA and TDMA }\end{array}$ & $\begin{array}{l}\text { QoS, energy consumption, } \\
\text { and channel utilisation }\end{array}$ & $\begin{array}{l}\text { Minimises energy consumption } \\
\text { and delay compared with } \\
\text { S-MAC, Q-MAC, and T-MAC }\end{array}$ & $\begin{array}{l}\text { Delay-sensitive monitoring } \\
\text { application }\end{array}$ \\
\hline $\begin{array}{l}\text { EDS-MAC } \\
\text { (Sundararaj } \\
\text { et al., 2018) }\end{array}$ & $\begin{array}{l}\text { Combination of } \\
\text { CSMA and TDMA }\end{array}$ & $\begin{array}{l}\text { Overhead, overhearing and } \\
\text { delay }\end{array}$ & $\begin{array}{l}\text { Minimises the overall delay, } \\
\text { overhead, overhearing and } \\
\text { energy consumption }\end{array}$ & $\begin{array}{l}\text { Real-time application with } \\
\text { high traffic loads }\end{array}$ \\
\hline
\end{tabular}

is done, each node has to decide the time frame during which it can utilise its time slot for communication. When a node has data for transmission, it verifies if it is the owner of the current time slot. If it finds itself as an owner, it assigns a random backoff period. When the backoff expires, it checks if the channel is free by running CCA. If the channel is free, it transmits its data. If the channel is busy, it waits until it finds the channel clear.

Z-MAC is very robust to slot assignment failures, synchronisation error and dynamic channel conditions. However, it needs global time synchronisation during the setup phase, which in turn causes energy consumption in sensor nodes.

\section{Adaptive CSMA/TDMA}

Gilani et al. (2013) proposed an IEEE 802.15.4-based MAC scheme, called adaptive CSMA/TDMA hybrid MAC protocol, to improve energy efficiency and data throughput in IEEE 802.15.4. Under high traffic scenario, the slotted CSMA/CA scheme employed in the beacon-enabled mode of 802.15.4 causes a significant amount of energy consumption and low throughput. To address these limitations, the proposed adaptive hybrid protocol introduces a dynamic TDMA period into the contention access period (CAP) of the superframe. With this method, the network coordinator node dynamically divides the CAP into the TDMA slots and slotted CSMA/CA based on the data queue status of nodes and the level of collisions occurred through the medium. The queue state information of the sensor nodes is obtained through the reserved bits in the data frames. As the coordinator is responsible of assigning TDMA slots among the sensor nodes, the two key issues associated with TDMA-based MAC scheme, namely synchronisation among nodes and the underutilisation problem in network, are resolved. The first issue is mostly resolved by the role of coordinator and the beacon frames that are periodically transmitted in the beacon interval. The second issue (also in high traffic scenario) is overcome by using the greedy algorithm to assign TDMA slots. One advantage of incorporating TDMA slots in CAP is, when a node is allocated with a TDMA slot, it does not transmit its data packet in the CSMA/CA period of the same beacon frame. Therefore, less number of nodes participate in the contention, and less number of collisions are occurred, which in turn improves throughput. Furthermore, as per the basic TDMA concept, the TDMA nodes turn their radio on only in their allocated time slots. This reduces the energy consumption of those nodes.

The simulation results in Gilani et al. (2013) indicate that the adaptive CSMA/TDMA hybrid MAC protocol reduces energy consumption and improves throughput as compared with IEEE 802.15.4 MAC. However, with long superframe duration being used, the TDMA nodes have to wait more time before transmitting their data packet, which in turn increase end-end delays.

\section{IH-MAC}

An energy-efficient and quality of service (QoS) guaranteed hybrid MAC protocol named intelligent hybrid MAC (IHMAC) is proposed in Arifuzzaman et al. (2013). IH-MAC is a CSMA/TDMA-based hybrid MAC approach that combines the strengths of each MAC category to improve energy efficiency under all traffic conditions, to shorten end-toend latency, and to ensure high channel utilisation under high traffics without limiting energy performance. The key features of IH-MAC include the utilisation of both broadcast scheduling and link scheduling to secure optimum utilisation of resources, the introduction of parallel transmission to reduce latency, and implementation of a decentralised TDMA concept. As per traffic loads, IH-MAC dynamically switches between link scheduling and broadcast scheduling to improve energy efficiency. With decentralised TDMA approach, each node locally utilises the clock arithmetic to find its allocated time slot. IH-MAC dynamically adapts node's transmit power to set it to the minimum level required to reach its intended receiver, thereby reducing energy consumption.

In IH-MAC, data packets are classified as per delay requirements and stored in the queue.IH-MAC divides the communication time into a number of slots or frames of fixed duration. Each frame is further divided into two periods: the active period and the sleep period. In each frame, the first part of the active period is called SYNC period in which SYNC packet is transmitted to maintain synchronisation among the sensor nodes within the cluster. The following part is for the data slot reservation. In the sleep period, sensor nodes transmit 
data packets and ACKs. The duty cycle should be carefully selected so that the sleep period is sufficiently large enough to send a data packet and ACK. In the sleep state, a sensor node turns off its power and sets a timer based on the duty cycle. When the timer is up, the sensor node switches to the wake-up state to listen to the data channel and remains in the idle listening state. If the node has data to transmit/receive, it switches to the CSMA/CA state. Otherwise, it goes back to the sleep state after a time-out. In CSMA/CA state, the sending node contends to access the channel. If it wins, both the sending node and its receiver go to the Tx/Rx (Transmit/Receive) state. After data communication, they go back to sleep state. Sensor nodes that fail to access the channel go back to sleep state.

Results in Arifuzzaman et al. (2013) indicate that IHMAC shows less energy consumption compared with SMAC and Q-MAC (Liu et al., 2005) under heavy and light traffics. Compared with T-MAC, IH-MAC shows better energy efficiency under heavy traffic loads. Furthermore, IH-MAC outperforms all of these three protocols in term of average packet delay.

\section{$E D S-M A C$}

An energy-efficient dynamic scheduling hybrid MAC protocol, namely EDS-MAC, is proposed in Sundararaj et al. (2018) for traffic-adaptive WSNs. EDS-MAC adapts the transmission power dynamically to minimise the energy wastage so as WSN lifetime can be maximised. EDS-MAC has two stages: cluster formation and data transmission. In the cluster formation stage, an algorithm, namely variable step size firefly algorithm (VSSFFA), is used in forming energyefficient clusters by efficiently selecting cluster heads. In the data transmission stage, data communication is performed. In EDS-MAC, a time slot consisting of active period and inactive (i.e., sleep) period is allocated to each member node. Each time slot begins with a SYNC period to provide synchronisation among nodes. When a sensor node receives a SYNC packet from another member node, it follows the scheduling information given in SYNC and sends its own SYNC. SYNC carries sender address and the schedule of its next sleep. After exchanging RTS/CTS successfully, the node goes to sleep. The sleep period carries both data and acknowledgement. The sleep period of the member nodes is chosen optimally large enough in order to allow data transmission together with acknowledgement.

Figure 14 (a) EDS-MAC and (b) IH-MAC (see online version for colours)

\begin{tabular}{|c|c|c|c|c|c|}
\hline SYNC & RTS/CTS & $\begin{array}{c}\text { Header } \\
1 \text { byte }\end{array}$ & DATA & $\begin{array}{c}\text { Priority } \\
1 \text { bit }\end{array}$ & ACK \\
\hline
\end{tabular}

a)

\begin{tabular}{|c|c|c|c|c|c|}
\hline SYNC & RTSiCTS & $\begin{array}{c}\text { Header } \\
\mathbf{8} \text { bytes }\end{array}$ & DATA & $\begin{array}{c}\text { Priority } \\
\mathbf{1} \text { bit }\end{array}$ & ACK \\
\hline
\end{tabular}

b)

In Sundararaj et al. (2018), EDS-MAC is compared with another hybrid protocol named IH-MAC (Arifuzzaman et al.,
2013). As shown in Figure 14, both IH-MAC and EDSMAC have the same duty cycle. However, as compared with EDS-MAC, IH-MAC has small segments allocated for data transmission, hence incurs more delay and control overhead. EDS-MAC minimises the control packet size by implementing short node address ( 1 byte). Results show that EDS-MAC minimises the overall delay, overhead, overhearing and energy consumption occurred in the entire network.

\section{Conclusion}

As WSN nodes are energy-constrained devices, the primary concern of WSNs is to minimise energy consumption to prolong the network lifetime. Though a number of energyefficient MAC protocols are proposed in the literature, there is no standard WSN MAC protocol. The choice of MAC protocol is generally application-specific. In this paper, a number of WSN MAC protocols proposed over 2000 to date are surveyed emphasising some general aspects including issues addressed, design principles, performances, strengths, drawbacks, and target applications. We primarily classify the MAC protocols into three categories, namely contention-based MAC, TDMAbased MAC, and hybrid MAC. Contention-based MAC is further divided into two subclasses named synchronous MAC and asynchronous MAC, where the later subclass is further subdivided into asynchronous MAC with one radio and MAC with WuR. The proposed taxonomy aims to identify the research trend and evolution of WSN MAC protocols based on distinct access mechanisms. Literature review shows that in the early stages, the main design issue was energy efficiency. However, in recent years, research attention has shifted to endto-end packet delivery delay and throughput to support WSN applications with bursty traffic without sacrificing energy efficiency. Furthermore, with the incorporation of energy harvesting techniques, recent MAC protocols are designed to achieve the best trade-off between energy efficiency and QoS such as throughput and delay.

Studies also show that contention-based duty-cycling MAC protocols improve energy efficiency; however, incur transmission delay, especially under heavy traffic loads. Synchronous duty cycling MAC schemes cause additional synchronisation overhead. Asynchronous MAC schemes eliminate synchronisation overhead as time synchronisation is not required herein. However, they need a coordination mechanism among nodes to determine the best wake-up time for data communication. The recent development trend is to shift the responsibility of establishing communication from the transmitter end to the receiver end in order to save cost at the transmitter side and improve throughput. Asynchronous MAC with WuR generally shows better performance in reducing energy consumption and latency. With two radio design, one big challenge is to enhance the wake-up range while completely removing battery usage to power up the passive WuR. With the receiver-initiated approach, one of the challenging issues is to reduce the idle listening of transmitters while ensuring the transmitter do not miss the wake-up beacon sent by the receiver. 
TDMA-based MAC protocols allow collision-free transmission and can provide improved throughput but at the cost of additional synchronisation overhead. Poor channel utilisation is another issue with TDMA-based MAC, which can be improved by adopting slot stealing technique. The considered hybrid MAC protocols try to combine the strengths of CSMA and TDMA-based MAC protocols while offsetting their limitations to attain better performance under dynamic traffic patterns. An important find out from this survey is that many WSN MAC protocols are designed without taking into consideration the effect of the network layer on overall system performance. Integration of layers can be an open research issue. Besides, recent MAC protocol designs encounter new challenges due to the introduction of energy harvesting devices in WSNs. MAC protocols for EH-WSNs must need to support adaptive duty cycle for individual nodes based on their available energy, which can be a potential research area.

\section{References}

Ahn, G-S., Hong, S.G., Miluzzo, E., Campbell, A.T. and Cuomo, F. (2006) 'Funneling-MAC: a localized, sink-oriented MAC for boosting fidelity in sensor networks', Proceedings of the 4th International Conference on Embedded Networked Sensor Systems, ACM, pp.293-306.

Akkaya, K. and Younis, M. (2005) 'A survey on routing protocols for wireless sensor networks', Ad Hoc Networks, Vol. 3, No. 3, pp.325-349.

Akyildiz, I.F., Su, W., Sankarasubramaniam, Y. and Cayirci, E. (2002) A Survey on Sensor Networks, August, pp.102-114.

Al Ameen, M., Islam, S. M.R. and Kwak, K. (2010) 'Energy saving mechanisms for MAC protocols in wireless sensor networks', International Journal of Distributed Sensor Networks, Vol. 6, No. 1, pp.163413.

Alfayez, F., Hammoudeh, M. and Abuarqoub, A. (2015) 'A survey on MAC protocols for duty-cycled wireless sensor networks', Procedia Computer Science, Vol. 73, pp.482-489.

Ali, M., Böhm, A. and Jonsson, M. (2008) 'Wireless sensor networks for surveillance applications-a comparative survey of MAC protocols', 2008 The Fourth International Conference on Wireless and Mobile Communications, IEEE, Athens, Greece, pp.399-403.

AlSkaif, T., Bellalta, B., Zapata, M.G. and Barcelo Ordinas, J.M. (2017) 'Energy efficiency of MAC protocols in low data rate wireless multimedia sensor networks: a comparative study', $A d$ Hoc Networks, Vol. 56, No. 1, pp.141-157.

Alvi, A.N., Bouk, S.H., Ahmed, S.H., Yaqub, M.A., Javaid, N. and Kim, D. (2015) 'Enhanced TDMA based MAC protocol for adaptive data control in wireless sensor networks', Journal of Communications and Networks, Vol. 17, No. 3, pp.247-255.

Alvi, A.N., Bouk, S.H., Ahmed, S.H., Yaqub, M.A., Sarkar, M. and Song, H. (2016) 'BEST-MAC: Bitmap-assisted efficient and scalable TDMA-based WSN MAC protocol for smart cities', IEEE Access, Vol. 4, pp.312-322.

Anchora, L., Capone, A., Mainetti, L., Mighali, V., Patrono, L. and Simone, F. (2016) 'AS2-MAC: an energy-efficient MAC protocol for wireless sensor networks', Adhoc and Sensor Wireless Networks, Vol. 31, Nos. 1-4, pp.199-226.
Arifuzzaman, M., Matsumoto, M. and Sato, T. (2013) 'An intelligent hybrid MAC with traffic-differentiation-based QoS for wireless sensor networks', IEEE Sensors Journal, Vol. 13, No. 6, pp.2391-2399.

Bachir, A., Dohler, M., Watteyne, T. and Leung, K.K. (2010) 'MAC essentials for wireless sensor networks', IEEE Communications Surveys and Tutorials, Vol. 12, No. 2, pp.222-248.

Boulfekhar, S., Bouallouche, L. and Benmohammed, M. (2012) 'S-TDMA: A new MAC protocol for wireless sensor networks', Proceedings - IEEE International Symposium on Distributed Simulation and Real-Time Applications, pp.29-35.

Buettner, M., Yee, G.V., Anderson, E. and Han, R. (2006) 'X-MAC: a short preamble MAC protocol for duty-cycled wireless sensor networks University of Colorado at Boulder X-MAC: a short preamble MAC protocol for duty-cycled', Work, Vol. 76, May, pp.307-320.

Buratti, C., Martalò, M., Verdone, R. and Ferrari, G. (2011) Sensor Networks with IEEE 802.15. 4 Systems: Distributed Processing, $M A C$, and Connectivity, Springer Science and Business Media.

Cano, C., Bellalta, B., Sfairopoulou, A. and Oliver, M. (2011) 'Low energy operation in WSNs: a survey of preamble sampling MAC protocols', Computer Networks, Vol. 55, No. 15, pp.3351-3363.

Carrano, R.C., Passos, D., Magalhaes, L. C.S. and Albuquerque, C. V.N. (2014) 'Survey and taxonomy of duty cycling mechanisms in wireless sensor networks', IEEE Communications Surveys Tutorials, Vol. 16, No. 1, pp.181-194.

Chen, K., Ma, M., Cheng, E., Yuan, F. and Su, W. (2014) 'A survey on MAC protocols for underwater wireless sensor networks', IEEE Communications Surveys and Tutorials, Vol. 16, No. 3, pp.1433-1447.

Cho, S., Kanuri, K., Cho, J-W., Lee, J-Y. and June, S-D. (2005) 'Dynamic energy efficient tdma-based MAC protocol forwireless sensor networks', Joint International Conference on Autonomic and Autonomous Systems and International Conference on Networking and Services-(ICAS-ISNS' 05), IEEE, Papeete, Tahiti, French Polynesia, p.48.

Czapski, P.P. (2006) 'A survey: MAC protocols for applications of wireless sensor networks', TENCON 2006-2006 IEEE Region 10 Conference, IEEE, pp.1-4.

Demirkol, I., Ersoy, C. and Alagöz, F. (2006) 'MAC protocols for wireless sensor networks: A survey', IEEE Communications Magazine, Vol. 44, No. 4, pp.115-121.

Djiroun, F.Z. and Djenouri, D. (2016) 'MAC protocols with wakeup radio for wireless sensor networks: A review', IEEE Communications Surveys and Tutorials, Vol. 19, No. 1, pp.587-618.

Du, S., Saha, A.K. and Johnson, D.B. (2007) 'RMAC: A routing-enhanced duty-cycle MAC protocol for wireless sensor networks', IEEE INFOCOM 2007-26th IEEE International Conference on Computer Communications, IEEE, pp.1478-1486.

El-Hoiydi, A. (2002) 'Aloha with preamble sampling for sporadic traffic in ad hoc wireless sensor networks', 2002 IEEE International Conference on Communications. Conference Proceedings. ICC 2002 (Cat. No. 02CH37333), Vol. 5, IEEE, pp.3418-3423.

El-Hoiydi, A. and Decotignie, J-D. (2005) 'Low power downlink MAC protocols for infrastructure wireless sensor networks', Mobile Networks and Applications, Vol. 10, No. 5, pp.675-690. 
Eu, Z.A., Tan, H-P. and Seah, W. K.G. (2011) 'Design and performance analysis of MAC schemes for wireless sensor networks powered by ambient energy arvesting', Ad Hoc Networks, Vol. 9, No. 3, pp.300-323.

Gilani, M. H.S., Sarrafi, I. and Abbaspour, M. (2013) 'An adaptive CSMA/TDMA hybrid MAC for energy and throughput improvement of wireless sensor networks', Ad Hoc Networks, Vol. 11, No. 4, pp.1297-1304.

Gobriel, S., Mosse, D. and Cleric, R. (2009) 'TDMA-ASAP: Sensor network TDMA scheduling with adaptive slot-stealing and parallelism', 2009 29th IEEE International Conference on Distributed Computing Systems, IEEE, pp.458-465.

Gutiérrez, J.A., Winkel, L., Callaway, E.H. and Barrett, R.L. (2010) Low-Rate Wireless Personal Area Networks: Enabling Wireless Sensors with IEEE 802.15.4, 3rd ed., Standards Information Network IEEE Press, New York, USA.

Han, X., Shu, L., Chen, Y. and Zhou, H. (2013) 'WX-MAC: an energy efficient MAC protocol for wireless sensor networks', 2013 IEEE 10th International Conference on Mobile Ad-Hoc and Sensor Systems, IEEE, Hangzhou, China, pp.423-424.

Heinzelman, W.R., Chandrakasan, A. and Balakrishnan, H. (2000) 'Energy-efficient communication protocol for wireless microsensor networks', Proceedings of the 33rd Annual Hawaii International Conference on System Sciences, IEEE, 10pp.

Henna, S. (2011) 'SA-RI-MAC: sender-assisted receiver-initiated asynchronous duty cycle MAC protocol for dynamic traffic loads in wireless sensor networks', International Conference on Mobile Lightweight Wireless Systems, Springer, Bilbao, Spain, pp.120-135.

Hsu, T.. and Yen, P. (2011) 'Adaptive time division multiple accessbased medium access control protocol for energy conserving and data transmission in wireless sensor networks', IET Communications, Vol. 5, No. 18, pp.2662-2672.

Huang, P., Xiao, L., Soltani, S., Mutka, M.W. and Xi, N. (2012) 'The evolution of MAC protocols in wireless sensor networks: A survey', IEEE Communications Surveys and Tutorials, Vol. 15, No. 1, pp.101-120.

Jang, B., Lim, J.B. and Sichitiu, M.L. (2013) 'An asynchronous scheduled MAC protocol for wireless sensor networks', Computer Networks, Vol. 57, No. 1, pp.85-98.

Kaur, T. and Kumar, D. (2016) 'TDMA-based MAC protocols for wireless sensor networks: a survey and comparative analysis', 2016 5th International Conference on Wireless Networks and Embedded Systems (WECON), IEEE, Rajpura, India, pp.1-6.

Khanafer, M., Guennoun, M. and Mouftah, H.T. (2013) 'A survey of beacon-enabled IEEE 802.15. 4 MAC protocols in wireless sensor networks', IEEE Communications Surveys and Tutorials, Vol. 16, No. 2, pp.856-876.

Kim, Y., Shin, H. and Cha, H. (2008) 'Y-mac: An energyefficient multi-channel MAC protocol for dense wireless sensor networks', Proceedings of the 7th International Conference on Information Processing in Sensor Networks, IEEE Computer Society, St. Louis, MO, USA, pp.53-63.

Kosunalp, S. (2015) 'MAC protocols for energy harvesting wireless sensor networks: Survey', ETRI Journal, Vol. 37, No. 4, pp.804-812.

Kosunalp, S. (2016) 'EH-TDMA: a TDMA-based MAC protocol for energy-harvesting wireless sensor networks', International Journal of Computer Science and Information Security, Vol. 14, No. 8, p.325.
Langendoen, K. (2008) 'Medium access control in wireless sensor networks', Medium Access Control in Wireless Networks, Vol. 2, pp.535-560.

Langendoen, K. and Meier, A. (2010) 'Analyzing MAC protocols for low data-rate applications', ACM Transactions on Sensor Networks, Vol. 7, No. 1, pp.1-34.

Li, J. and Lazarou, G.Y. (2004) 'A bit-map-assisted energy-efficient MAC scheme for wireless sensor networks', Proceedings of the 3rd International Symposium on Information Processing in Sensor Networks, ACM, pp.55-60.

Liang, L., Liu, X., Wang, Y., Feng, W. and Yang, G. (2014) 'SWMAC: a low-latency MAC protocol with adaptive sleeping for wireless sensor networks', Wireless personal communications, Vol. 77, No. 2, pp.1191-1211.

Liu, C-J., Huang, P. and Xiao, L. (2016) 'TAS-MAC: A trafficadaptive synchronous MAC protocol for wireless sensor networks', ACM Transactions on Sensor Networks (TOSN), Vol. 12, No. 1, pp.1-30.

Liu, S., Fan, K-W. and Sinha, P. (2009) 'CMAC: An energy-efficient MAC layer protocol using convergent packet forwarding for wireless sensor networks', ACM Transactions on Sensor Networks, Vol. 5, No. 4, pp.1-34.

Liu, Y., Elhanany, I. and Qi, H. (2005) 'An energy-efficient QoS-aware media access control protocol for wireless sensor networks', IEEE International Conference on Mobile Adhoc and Sensor Systems Conference, 2005, IEEE, Washington, DC, USA, 3pp.

Lu, G., Krishnamachari, B. and Raghavendra, C.S. (2004) 'An adaptive energy-efficient and low-latency MAC for data gathering in wireless sensor networks', Proceedings of thte 18th International Parallel and Distributed Processing Symposium, 2004, Vol. 18, IEEE, pp.3091-3098.

Matin, M.A. and Islam, M.M. (2012) 'Overview of Wireless Sensor Network, IntechOpen.

Mazloum, N.S. and Edfors, O. (2011) 'DCW-MAC: an energy efficient medium access scheme using duty-cycled lowpower wake-up receivers', 2011 IEEE Vehicular Technology Conference (VTC Fall), IEEE, San Francisco, CA, USA, pp.1-5.

Miller, M.J. and Vaidya, N.H. (2004) 'Minimizing energy consumption in sensor networks using a wakeup radio', 2004 IEEE Wireless Communications and Networking Conference (IEEE Cat. No. 04TH8733), Vol. 4, IEEE, pp.2335-2340.

Morshed, S. and Heijenk, G. (2014) 'TR-MAC: An energy-efficient MAC protocol exploiting transmitted reference modulation for wireless sensor networks', Proceedings of the 17th ACM International Conference on Modeling, Analysis and Simulation of Wireless and Mobile Systems, ACM, Montreal, QC, Canada, pp.21-29.

Muzakkari, B.A., Mohamed, M.A., Kadir, M. F.A., Mohamad, Z. and Jamil, N. (2018) 'Recent advances in energy efficientQoS aware MAC protocols for wireless sensor networks', International Journal of Advanced Computer Research, Vol. 8, No. 38, pp.212-228.

Naik, P. and Sivalingam K.M. (2004) 'A survey of MAC protocols for sensor networks', in Raghavendra, C.S., Sivalingam, K.M. and Znati, T. (Eds.): Wireless Sensor Networks, Springer, Boston, MA, pp.93-107.

Pal, P.K. and Chatterjee, P. (2014) 'A survey on TDMA-based MAC protocols for wireless sensor network', International Journal of Emerging Technology and Advanced Engineering, Vol. 4, No. 6, pp.219-230. 
Pegatoquet, A., Le, T.N. and Magno, M. (2019) 'A wake-up radio-based MAC protocol for autonomous wIRELESS sensor networks', IEEE/ACM Transactions on Networking, Vol. 27, No. 1, pp.56-70.

Pei, G. and Chien, C. (2001) 'Low power TDMA in large wireless sensor networks', 2001 MILCOM Proceedings Communications for Network-Centric Operations: Creating the Information Force (Cat. No. 01CH37277), Vol. 1, IEEE, pp.347-351.

Polastre, J., Hill, J. and Culler, D. (2004) 'Versatile low power media access for wireless sensor networks', Proceedings of the 2nd International Conference on Embedded Networked Sensor Systems, ACM, Baltimore, MD, USA, pp.95-107.

Quintero, V., Estevez, C., Orchard, M. and Pérez, A. (2019) 'Improvements of energy-efficient techniques in WSNs: a MAC-protocol approach', IEEE Communications Surveys and Tutorials, Vol. 21, No. 2, pp.1188-1208.

Rajendran, V., Obraczka, K. and Garcia-Luna-Aceves, J.J. (2006) 'Energy-efficient, collision-free medium access control for wireless sensor networks', Wireless networks, Vol. 12, No. 1, pp.63-78.

Rhee, I., Warrier, A., Aia, M., Min, J. and Sichitiu, M.L. (2008) 'ZMAC: a hybrid MAC for wireless sensor networks', IEEE/ACM Transactions on Networking (TON), Vol. 16, No. 3, pp.511-524.

Schurgers, C., Tsiatsis, V., Ganeriwal, S. and Srivastava, M. (2002) 'Topology management for sensor networks: Exploiting latency and density', Proceedings of the 3rd ACM International Symposium on Mobile Ad Hoc Networking and Computing, ACM, Lausanne, Switzerland, pp.135-145.

Shafiullah, G.M., Azad, S.A. and Ali, A.B.M.S. (2013) 'Energyefficient wireless MAC protocols for rAILWAY monitoring applications', IEEE Transactions on Intelligent Transportation Systems, Vol. 14, No. 2, pp.649-659.

Shafiullah, G.M., Thompson, A., Wolfs, P.J. and Ali, S. (2008) Energy-efficient TDMA MAC protocol for wireless sensor networks applications', 2008 11th International Conference on Computer and Information Technology, pp.85-90.

Sherazi, H.H.R., Grieco, L.A. and Boggia, G. (2018) 'A comprehensive review on energy harvesting MAC protocols in WSNs: challenges and tradeoffs', Ad Hoc Networks, Vol. 71, pp.117-134.

Song, W-Z., Huang, R., Shirazi, B. and LaHusen, R. (2009) 'TreeMAC: localized TDMA MAC protocol for real-time highdata-rate sensor networks', Pervasive and Mobile Computing, Vol. 5, No. 6, pp.750-765.

Sreejith, V. and Gudino, L.J. (2016) DS-MMAC: Dynamic Schedule based MAC for Mobile Wireless Sensor Network Problem Definition with Assumptions, pp.738-741.

Sun, Y., Gurewitz, O. and Johnson, D.B. (2008) 'RI-MAC: a receiverinitiated asynchronous duty cycle MAC protocol for dynamic traffic loads in wireless sensor networks', Proceedings of the 6th ACM conference on Embedded Network Sensor Systems, ACM, pp.1-14.

Sundararaj, V., Muthukumar, S. and Kumar, R.S. (2018) 'An optimal cluster formation based energy efficient dynamic scheduling hybrid MAC protocol for heavy traffic load in wireless sensor networks', Computers and Security, Vol. 77, pp.277-288.
Suriyachai, P., Roedig, U. and Scott, A. (2011) 'A survey of MAC protocols for mission-critical applications in wireless sensor networks', IEEE Communications Surveys and Tutorials, Vol. 14, No. 2, pp.240-264.

Tang, L., Sun, Y., Gurewitz, O. and Johnson, D.B. (2011) 'PWMAC: an energy-efficient predictive-wakeup MAC protocol for wireless sensor networks', 2011 Proceedings IEEE INFOCOM, IEEE, pp.1305-1313.

Van Dam, T. and Langendoen, K. (2003) 'An adaptive energyefficient MAC protocol for wireless sensor networks', Proceedings of the 1st International Conference on Embedded Networked Sensor Systems, ACM, Los Angeles, California, USA, pp.171-180.

van Hoesel, L.F.W., Nieberg, T., Kip, H.J. and Havinga, P.J.M. (2004) 'Advantages of a TDMA based, energy-efficient, selforganizing MAC protocol for WSNs', 2004 IEEE 59th Vehicular Technology Conference. VTC 2004-Spring (IEEE Cat. No. 04CH37514), Vol. 3, IEEE, pp.1598-1602.

Wang, G., Yu, J., Yu, D., Yu, H. and Feng, L. (2015) 'DS-MAC: an energy efficient demand sleep MAC protocol with low latency for wireless sensor networks', Journal of Network and Computer Applications, Vol. 58, pp.155-164.

Ye, W., Heidemann, J. and Estrin, D. (2002) 'An energy-efficient MAC protocol for wireless sensor Networks', Proceedings of the \{IEEE $\}$ Infocom, pp.1567-1576.

Ye, W., Heidemann, J. and Estrin, D. (2004) 'Medium access control with coordinated adaptive sleeping for wireless sensor networks', IEEE/ACM Transactions on Networking (ToN), Vol. 12, No. 3, pp.493-506.

Ye, W., Silva, F. and Heidemann, J. (2006) 'Ultra-low duty cycle MAC with scheduled channel polling', Proceedings of the 4th International Conference on Embedded Networked Sensor Systems, ACM, Boulder, Colorado, USA, pp.321-334.

Yigitel, M.A., Incel, O.D. and Ersoy, C. (2011) 'QoS-aware MAC protocols for wireless sensor networks: a survey', Computer Networks, Vol. 55, No. 8, pp.1982-2004.

Zhao, Y.Z., Miao, C., Ma, M., Zhang, J.B. and Leung, C. (2012) 'A survey and projection on medium access control protocols for wireless sensor networks', ACM Computing Surveys (CSuR), Vol. 45, No. 1, pp.7.

Zheng, G., Fu, J., Tang, S., Li, Y. and Dong, Z. (2010) 'A dual channelbased energy efficient and low latency MAC protocol for wsns', 2010 Second International Conference on Networks Security, Wireless Communications and Trusted Computing, Vol. 1, IEEE, Wuhan, Hubei, China, pp.466-469.

Zorzi, M. and Rao, R.R. (2003) 'Geographic random forwarding $(\mathrm{GeRaF})$ for ad hoc and sensor networks: energy and latency performance', IEEE Transactions on Mobile Computing, Vol. 2 , No. 4, pp.349-365.

Zurawski, R. (Ed.) (2017) Embedded Systems Handbook: Networked Embedded Systems, 2nd ed., CRC Press, Boca Raton, FL, USA. 